ISSN 0819-2642

ISBN 9780734040107

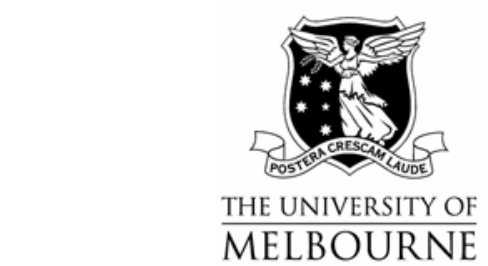

THE UNIVERSITY OF MELBOURNE

DEPARTMENT OF ECONOMICS

RESEARCH PAPER NUMBER 1044

February 2008

Costly External Finance, Reallocation, and Aggregate Productivity

by

Shuyun May Li

Department of Economics

The University of Melbourne

Melbourne Victoria 3010

Australia. 


\title{
Employment Flows with Endogenous Financing Constraints
}

\author{
Shuyun May Li* \\ Department of Economics \\ The University of Melbourne \\ Victoria, 3010, Australia \\ Tel: $61-3-83445316$ \\ Fax: 61-3-83446899 \\ shuyunl@unimelb.edu.au \\ May 2008
}

*I thank my Ph.D. supervisor, Dean Corbae, for his valuable guidance. I also thank Russell Cooper, Burhan Kuruscu, Gian Luca Clementi, John Haltiwanger, Patrick Kehoe, and seminar participants at the University of Texas at Austin and the University of Melbourne for helpful comments. All errors are my own. 


\begin{abstract}
This paper develops an industry evolution model to explore the quantitative implications of endogenous financing constraints for job reallocation. In the model firms finance entry costs and per period labor costs with long-term financial contracts signed with banks, which are subject to asymmetric information and limited commitment problems. Financing constraints arise as a feature of the optimal contract. The model generates endogenous firm exit and job reallocation in a stationary industry equilibrium. A quantitative analysis shows that endogenous financing constraints can account for a substantial amount of job reallocation observed in U.S. manufacturing and the observed negative relationship between job reallocation rates and firm size as measured by employment.
\end{abstract}

Keywords: Asymmetric information; Limited liability; Limited commitment; Dynamic contract; Job reallocation; Stationary competitive equilibrium; Stationary firm distribution.

JEL classification: E24, D82, L14 


\section{Introduction}

This paper explores the quantitative implications of financial frictions for simultaneous expansion and contraction across firms and the resultant reallocation of employment. The quantitative significance of such reallocation is reflected in the high turnover rates of jobs and firms. Davis, Haltiwanger and Schuh (1998) document that on average 10.3 percent of manufacturing jobs were destroyed and 9.1 percent were created per annum during the 197388 period. And during the same period, according to the Census of Manufactures, over forty percent of the manufacturing firms disappeared over five year periods and were replaced by new ones. Empirical studies, such as Evans (1987), Hall (1987), Dunne, Roberts and Samuelson (1989), and Davis, et al (1996), also find interesting regularities in the turnover. Notably, firm exit rates, job creation, destruction and reallocation rates are decreasing in firm size (measured by employment) and age.

Despite the economic and social significance, economic theories underlying the turnover have not been fully developed. Existing labor market theories, including labor demand models with adjustment costs of labor and search theories of equilibrium job flows, have difficulty accounting for the negative size and age dependence of gross employment flows. Recent developments in the theory of firm dynamics and industry evolution have shed some light on this problem. The learning theory of Jovanovic (1982) has the potential to account for the negative age dependence of the turnover. Hopenhayn (1992) introduces persistent idiosyncratic technology shocks to drive the entry, exit and size dynamics of firms. This model can explain the negative dependence of firm exit rates on firm size. However, as pointed out by Cooley and Quadrini (2001), without some restrictions on the transition probabilities of the shock process, it is hard to derive a general pattern of job reallocation on firm size.

This paper studies firm dynamics from another angle: frictions in firm financing and the resultant financing constraints. There is considerable empirical evidence suggesting that financing constraints might be important determinants of firm dynamics (see Fazzari, Hubbard and Peterson (1988), Gilchrist and Himmelberg (1995) and Whited (1992)). Recent work by Cooley and Quadrini (2001), Albuquerque and Hopenhayn (2004), Clementi and Hopenhayn (2006), and etc., have also shown that models of firm dynamics that incorporate exogenous or endogenous financing constraints into a firm's decisions are qualitatively consistent with some stylized facts on the growth and survival of firms. In particular, Cooley and Quadrini (2001) introduce financial market frictions into the basic framework of Hopenhayn (1992) and show that the integration of persistent technology shocks and financial frictions allow the model to generate simultaneous dependence of firm dynamics on size and age ${ }^{1}$. This paper follows the same line of research as these studies, but aims to quantitatively evaluate the significance of financing constraints for job reallocation, something that has not been addressed in the literature so far. Specifically, two quantitative questions are addressed. First, how much job reallocation can be accounted for by financing constraints? Second, how much of the negative size and age dependence of job reallocation can be accounted for by financing constraints?

\footnotetext{
${ }^{1}$ In Cooley and Quadrini (2001), firm size is measured by capital. Since labor and capital are assumed to be complements, the size dependence also holds if size is measured by employment.
} 
To address these questions, this paper develops an industry equilibrium model in which firms' entry, exit, expansion and contraction are driven by financing constraints. A comparison with Cooley and Quadrini (2001) is that we explicitly model the micro foundations of financing constraints while there the financing constraints in one-period external finance arise from two exogenous assumptions on financial market imperfections and firm exit is assumed to be exogenous. In the model constructed, firms' growth and failure are fully driven by the endogenous financing constraints, and firm entry, exit and job reallocation emerge in a stationary industry equilibrium. The model is then calibrated and simulations are implemented to answer the quantitative questions outlined earlier.

In the model, firms are endowed with identical risky projects that require a fixed initial investment that firms cannot afford with their initial wealth and per period labor inputs to produce a homogeneous product at each period. Entrepreneurs are assumed to have private information about the outcomes of their production, where the idiosyncratic production shocks are assumed to be i.i.d. across firms and time. A firm can be liquidated at the beginning of a period and generate a positive scrap value. Upon entry, a firm signs a longterm financial contract with a competitive bank which finances its initial investment and per period wage bills in exchange for repayments from the firm in every period. A firm's life cycle (employment growth and failure) is completely regulated by the optimal financial contract in relation to its shock realizations.

The contracting problem is a modification of Clementi and Hopenhayn (Hereafter $\mathrm{C}-\mathrm{H}$ ) (2006), where they model borrowing constraints as an equilibrium outcome of a long-term borrowing/lending contract with asymmetric information between a firm and a bank and characterize the firm dynamics implied by the optimal contract. The model predicts that on average smaller firms are more financially constrained, grow faster but the growth is more volatile, and have higher probability of being liquidated. These implications are consistent with the qualitative properties of firm dynamics documented recently. However, the contract predicts that the firm repays all revenues to the bank until it is liquidated or it grows to a stage where the bank advances the unconstrained efficient amount of working capital to the firm in every period while the firm pays nothing back to the bank. This feature of the contract has several implications that are inconsistent with the data. First, it implies that a firm, if not liquidated at an early stage of its life, will grow in finite periods to reach its unconstrained efficient size and never be liquidated. While in the data, one observes even large firms going bankrupt and adjusting scales of operation. Second, once a firm grows to the unconstrained stage, the bank it signs the contract with will lose from the contract forever. It seems unrealistic that banks do not impose any control over this situation in the first place or renegotiate the contract afterwards considering that the Clementi and Hopenhayn contract is not renegotiation-proof ${ }^{2}$. Finally, in an industry equilibrium model, if firms are financed by this type of contracts, all incumbent firms would eventually attain the same efficient size. There would be no firm entry, exit, or job reallocation in a stationary industry equilibrium.

The assumption underlying this result is the full commitment of the bank. In Clementi

\footnotetext{
${ }^{2}$ The existence of people's retirement account may be used against this argument since its balance may become negative when people draw from this account after retirement such that the bank loses from this account until the person dies. However, a key difference here is that people have a finite life-span while firms that grow to that stage last forever.
} 
and Hopenhayn (2006) the entrepreneur is assumed to have limited commitment in the sense that she has limited liability for repayments in every period, while the bank is assumed to be able to keep her promises under all circumstances. Despite that full commitment is typically assumed for banks (the principal) in existing literature on optimal lending contract between firms and banks (e.g. see Albuquerque and Hopenhayn (2004), Quadrini (2003), and Cooley and Quadrini (2004)), it implies unlimited liability of the bank in the current context, which is far from being realistic. As pointed out in Sinn (2001), banks enjoy the privilege of limited liability (BLOOS rule) as all corporations do ${ }^{3}$. To account for this, we modify the Clementi and Hopenhayn contract by assuming that a bank is guaranteed a zero continuation value from a contract from every period onward, as an entrepreneur does (the limited liability of firms imply a nonnegative continuation value of a contract to an entrepreneur from every period onward). That is, the continuation value of a contract to a bank at the beginning of any period is required to be nonnegative. A zero lower bound may seem arbitrary or restrictive. However, assuming a negative lower bound on the continuation value of a contract to a bank would not change the crucial features of the model as long as the lower bound is greater than the continuation value of the Clementi and Hopenhayn contract to the bank when the firm grows to the unconstrained stage. With this modification, firms will never reach the unconstrained stage where banks lose from the contracts forever.

Technically, this constraint is equivalent to assuming that banks have limited commitment for the Clementi and Hopenhayn contract such that a bank would renege on a contract without punishment if the continuation value of the contract to herself falls below zero. For this reason we will refer to this constraint as limited commitment of banks. However it should be emphasized that this does not contradict the common belief that banks can fully honor their contracts since banks do have full commitment for the modified contract. A lemma shows that the limited commitment constraint for banks can be reduced to an upper bound on the value of the contract to an entrepreneur (the state variable in the recursive formulation of the dynamic contract), which ensures the tractability of the contracting problem. Firm dynamics implied by the optimal contract share some features as C-H (2006), for instance, smaller firms tend to be more financially constrained and have higher probability of being liquidated. However, the limiting behavior has been changed by the assumed limited commitment of banks. That is, a firm is financing constrained and has positive probabilities of being liquidated throughout its life cycle. These features are crucial for generating endogenous firm entry, exit and job reallocation in the stationary industry equilibrium. The optimal contract also predicts more realistic decision rules concerning a firm's dividend and repayment policy.

Notice that the contracting problem considered here is one with repeated moral hazard and two-sided limited commitment. This provides a theoretical contribution to existing literature on risk sharing contracts between an agent and a principal, where most studies assume full commitment of both parties (e.g., see Green (1987), Atkeson and Lucas (1992), and Spear and Srivastava (1987)) or lack of commitment on the agent's side (e.g., see Phelan (1995) and Krueger and Uhlig (2006)). This paper considers lack of commitment on the

\footnotetext{
${ }^{3}$ Limited liability of banks is often characterized by the term "BLOOS rule" after the English proverb "You can't get blood out of a stone". There is substantial work on implications of limited liability of banks for bank behavior, financial crises, banking regulations and so on (e.g. see Repullo (2004), Sinn (2001), and Gollier, et al. (1997)).
} 
principal's side in the context of C-H (2006), justified by limited liability of banks, and shows that it implies interesting firm dynamics that are in line with the data. A key novelty here is that the limited commitment assumption for the principal puts an upper bound on expected utilities of the agent (value of the contract to the firm) so as to generate a nondegenerate limiting distribution of agents with mobility. This is an alternative to existing approaches in the literature, where nondegenerate limiting distributions are obtained by imposing different discount rates for the principal and the agent (see Aiyagari and Willamson (1999)) or a lower bound on expected utilities of agents (see Atkeson and Lucas (1995) and Phelan (1995)).

The model is shown to possess a unique stationary competitive equilibrium with firm entry and exit in which aggregate employment is constant while individual firms continually adjust employment levels. In contrast, the equilibrium without the financing frictions exhibits no firm entry or exit, with all firms employing the same efficient amount of labor. Therefore, the employment dynamics in the model are fully driven by the financial frictions. The baseline calibration picks key parameters to match the exit rate, employment share and relative size of exiting firms due to bankruptcy and liquidation for the U.S. manufacturing. The model generates an annual job reallocation rate of $9.5 \%$, which is nearly $50 \%$ of the job reallocation rate $(19.4 \%)$ documented in the data. Furthermore, the correlation coefficient between average firm size and job reallocation rate is -0.51 , slightly lower than its data counterpart $(-0.59)$ in magnitude, which implies that $87 \%$ of the negative size dependence of job reallocation can be accounted for by the financial frictions in the model. The model also generates an unconditional negative age dependence of job reallocation (But once controlled for firm size, age dependence disappears).

Finally, it should be emphasized that contrary to the creative nature of job reallocation driven by technology shocks, as in Hopenhayn and Rogerson (1993), job reallocation in this model is not creative or efficient. Firms in the model have identical technology. Without the financial frictions, they would produce at the same efficient level, and no firm would exit. The presence of financial frictions causes inefficient job reallocation across firms, and results in considerable losses in aggregate output and employment. The quantitative significance of these impacts may justify the intensified exercise of government watchdog accounting procedures at the Securities and Exchange Commission. A comparative static analysis is also implemented to see how these impacts vary with the discount factor, project riskiness, and other primitives of the model. The results show that the model exhibits comparative static properties that are consistent with the data and existing literature.

The rest of the paper is arranged as follows. Section 2 describes the model. Section 3 characterizes the equilibrium, in particular, the optimal financial contract. Section 4 describes the results of the quantitative analysis. Section 5 concludes.

\section{The Environment}

Time is discrete and the horizon is infinite. The industry is composed of a continuum of firms and banks. In each period, a continuum of infinitely lived entrepreneurs are born with net worth $M$ and a risky project, which requires an initial fixed investment $I>M$ and per-period labor input to produce a homogeneous product. The labor cost must be paid before production. Projects are subject to idiosyncratic production shocks $\theta_{t}$ in each period, 
where $\theta_{t} \in\{H, L\}$ with $\operatorname{prob}\{\theta=H\}=\pi$. If $\theta_{t}=H$, a project produces output $f\left(l_{t}\right)$, where $l_{t}$ is the number of workers employed in period $t$. The function $f$ is continuous, strictly increasing and strictly concave. If $\theta_{t}=L$, output in period $t$ is zero. Production shocks are assumed to be independent across time and projects. A project can be scrapped at the beginning of a period, in which case it generates a positive scrap value $S$. It is assumed that $S<I-M$.

As in C-H (2006), realizations of production shocks are assumed to be private information of the entrepreneur who manages the project. Outsiders cannot observe or verify it. Since $I>M$, an entrepreneur needs the financial services of banks to undertake her project. As discussed in $\mathrm{C}-\mathrm{H}(2006)$, the presence of asymmetric information gives rise to a long-term credit relationship between an entrepreneur and a bank, under which the bank provides funds for the entrepreneur to finance the initial investment and per-period labor cost of the project in exchange for repayments from the entrepreneur. In every period an entrepreneur is assumed to be liable for repayments only to the extent of current revenues. This is the limited liability constraint for entrepreneurs. The remaining revenues are fully consumed by the entrepreneur (dividends of the firm). The assumed limited commitment constraint for banks that is crucial for the model states that the continuation value of a contract to a bank at the beginning of any period is required to be nonnegative. The optimal contract subject to these constraints is carefully defined and characterized in Section 3.

Banks are competitive and infinitely-lived. They participate in the long-term credit market in which they provide funds for entrepreneurs in exchange for repayments. They also have access to an external one-period credit market which opens at the end of each period, where they can freely borrow or lend funds at interest rate $r$. Entrepreneurs are excluded from this market ${ }^{4}$. Throughout the discussion, banks are summarized into a single agent that contracts with all entrepreneurs.

In every period a new-born entrepreneur is offered with lifetime contracts by the bank. If she accepts a contract, her project gets financed and a new firm enters the industry. From then on, she simply follows the contract for labor, repayment and dividend decisions. If her firm gets liquidated, the entrepreneur exits the industry and never enters again. If she does not accept any contract, she stays out of the industry and simply consumes her initial wealth.

Incumbent firms behave competitively, taking prices in the output $(p)$ and labor $(w)$ markets as given. Aggregate demand for the product is given by the inverse demand function, $p=D(Q)$, where the function $D$ is continuous, strictly decreasing, and satisfies $\lim _{Q \rightarrow \infty} D(Q)=0$. Following Hopenhayn and Rogerson (1993), the wage rate is normalized to be $1, w=1$.

Both entrepreneurs and banks are risk neutral, and discount future cash flows at the same rate $\beta=1 /(1+r)$.

The timing of events in one period is summarized as follows. At the beginning of a period, some incumbent firms are scrapped and exit the industry, and some new firms enter. Firms then hire labor from the competitive labor market and pay wage bills with loans from the bank. Production is undertaken and production shocks are realized for every

\footnotetext{
${ }^{4}$ Actually due to the information structure, one-period credit relationship with entrepreneurs is not feasible.
} 
firm. Entrepreneurs sell output in the product market, and make reports about production outcomes to the bank. Conditional on their reports, revenues are divided between the bank and entrepreneurs. Finally, the bank borrows or lends in the re-opened one-period credit market.

\section{Equilibrium}

A stationary equilibrium is considered. Since there is no aggregate uncertainty, a constant output price of $p$ is assumed. To facilitate an understanding of how the presence of asymmetric information affects the dynamics of a firm and the industry, we first consider the case of symmetric information, where the bank also observes the production shocks of firms.

\subsection{Symmetric Information}

Since all entrepreneurs are identical at birth, the bank offers them the same optimal lifetime contract in equilibrium. Once an entrepreneur accepts the contract, the bank provides funds of $I-M$ to help finance the initial investment of her project. The contract also specifies how much funds the bank provides in each period for the firm to employ labor, how much the firm has to repay the bank in each period, and under what conditions the firm is scrapped. With symmetric information, the optimal contract achieves the first-best outcome, i.e., the bank provides an entrepreneur with funds to employ the unconstrained efficient amount of labor in each period, which is given by

$$
l^{\star}(p) \equiv \operatorname{argmax}_{l} \quad \pi p f(l)-l .
$$

Then the total value of the contract, defined as the total expected discounted value of future net cash flows from the project, is given by

$$
\tilde{W}(p)=\frac{\pi p f\left(l^{\star}(p)\right)-l^{\star}(p)}{1-\beta} .
$$

It is divided between the bank and the entrepreneur. Denote the value of the contract to the entrepreneur (the entrepreneur's claim to future cash flows) by $V$. Following C-H (2006), $V$ is also called the firm's equity value throughout the discussion. Then

$$
V=\frac{\pi\left(p f\left(l^{\star}(p)\right)-\tau\right)}{1-\beta},
$$

where $\tau$ is the entrepreneur's repayment to the bank in a period if her production is successful in that period (Due to limited liability, the entrepreneur does not need to pay anything if her project fails in that period). For a given $p, \tau$ can be determined by (3) and the free entry condition of firms, which equates the value of the contract to the entrepreneur to her initial wealth,

$$
V=M
$$

To determine the equilibrium output price $p$, consider the value of the contract to the bank,

$$
B(V)=\tilde{W}(p)-V .
$$


Competition among banks imply that

$$
B(V)=I-M
$$

Recall that $I-M$ is what the bank has to pay to undertake the project ${ }^{5}$, so (6) states that there is no gain for the bank from participating in the contract. Since $I>M, B(V)>0$, and hence the limited commitment constraint for the bank is satisfied. Eq. (4)-(6) imply that

$$
\tilde{W}(p)=I .
$$

This pins down the equilibrium output price $p$. The total demand for the output is thus given by

$$
Q=D^{-1}(p) .
$$

The size of the industry or the total mass of incumbent firms $N$ is then determined by

$$
Q=N \pi f\left(l^{\star}(p)\right) .
$$

Since $S<I-M$, the bank never scraps an incumbent firm. So in equilibrium, firms with total mass of $N$ stay in the industry, hiring the efficient amount of labor and producing the efficient level of output in every period. There is no firm entry and exit. Incumbent firms never expand or contract. Hence there is no job creation or destruction.

\subsection{The Optimal Financial Contract with Asymmetric Informa- tion}

Again since entrepreneurs are ex-ante identical, in equilibrium the bank offers them the same optimal contract. Without loss of generality, consider the contracting problem between the bank and an entrepreneur born at period 0. Conditional on the history of reports of the entrepreneur, $h^{t}=\left(\hat{\theta}_{0}, \hat{\theta}_{1}, \ldots, \hat{\theta}_{t}\right)$, the contract specifies a contingent policy of liquidation probabilities $\alpha_{t}\left(h^{t-1}\right)$, transfers from the bank to the entrepreneur in case of liquidation $X_{t}\left(h^{t-1}\right)$, labor input $l_{t}\left(h^{t-1}\right)$, and repayments from the entrepreneur to the bank in case of no liquidation $\tau_{t}\left(h^{t}\right)$ to maximize the value of the contract to the bank, subject to a set of conditions.

Without the limited commitment constraint for the bank, the contracting problem would essentially be the same as C-H (2006). It possesses a recursive formulation, taking the entrepreneur's value entitlement (the value of the contract to the entrepreneur) at the beginning of a period, $V$, as the state variable. With limited commitment of the bank, a recursive formulation is not so straightforward. The optimal contract must be such that the value of the contract to the bank at the beginning of any period is non-negative conditional on any history of reports of the entrepreneur. A contract like C-H(2006) does not satisfy this constraint. For instance, it predicts that if the project is not scrapped at an early stage, $V$ will eventually reach $\tilde{V}(p) \equiv \frac{\pi p f\left(l^{\star}(p)\right)}{1-\beta}$. Thereafter, the firm will produce at the unconstrained efficient level in every period. Note that at $\tilde{V}(p)$, the value of the contract to the bank is

\footnotetext{
${ }^{5}$ If instead the bank invests this amount of funds in the one-period credit market, the present value of this investment to the bank would also be $I-M$, since $\beta=\frac{1}{1+r}$.
} 
$\tilde{W}(p)-\tilde{V}(p)<0$. Intuitively, the limited commitment constraint is equivalent to putting an upper bound on the value of the contract to the entrepreneur at the beginning of any period, since the total value of the contract is bounded above by $\tilde{W}(p)$, which is the total value of the unconstrained efficient contract as defined in Eq. (2). Denote this upper bound as $\bar{V}$ and take it as given for the moment. Then the optimal contract has a recursive formulation with $V \leq \bar{V}$ as the state variable. This argument is consistent with Phelan (1995), where he considers an insurance contract between a firm and an agent with privately observed endowments, assuming that both parties can walk away from the contract at the beginning of a period (with or without cost), and he shows that the two limited commitment constraints can boil down to a restriction on the set of feasible continuation utilities for the agent such that the efficient contract is recursive.

Note that $V$ is also bounded below by zero because the limited liability constraint ensures the entrepreneur a non-negative net cash flow in every period. For a given $V \in[0, \bar{V}]$, the bank's problem is to choose the choice variables to maximize $B(V)$, the value of the contract to herself, or equivalently, to maximize the total value, $W(V) \equiv V+B(V)$. The first choice to be made is whether to liquidate the project, obtaining the scrap value $S$, or keep it in operation. If the project is not scrapped, the problem for the continuation stage is to choose labor input, repayment to the bank, and etc. For a given output price $p$, a recursive formulation for the liquidation problem is given by

$$
\begin{array}{cl}
\left(P_{1}\right) \quad W(V ; p)= & \max _{\alpha \in[0,1], X, V_{c}}\left\{\alpha S+(1-\alpha) \hat{W}\left(V_{c} ; p\right)\right\} \\
\text { subject to } & \\
& V=\alpha X+(1-\alpha) V_{c} \\
& X \geq 0, V_{c} \geq 0 .
\end{array}
$$

Here, $\alpha$ is the liquidation probability. As argued in $\mathrm{C}-\mathrm{H}(2006)$, a stochastic liquidation would be optimal due to the non-convexity introduced by a constant scrap value. $X$ is the transfer from the bank to the entrepreneur in case of liquidation. $V_{c}$ is the value entitlement to the entrepreneur at the continuation stage if her firm is not liquidated. Eq. (8) is a promise-keeping constraint, stating that the contract delivers an expected value equal to $V$ to the entrepreneur such that the bank's promise to the entrepreneur is fulfilled.

A recursive formulation for the continuation problem is given by

$$
\left(P_{2}\right) \quad \hat{W}\left(V_{c} ; p\right)=\max _{l, \tau, V^{H}, V^{L}}\left\{\pi p f(l)-l+\beta\left\{\pi W\left(V^{H} ; p\right)+(1-\pi) W\left(V^{L} ; p\right)\right\}\right\}
$$

subject to

$$
\begin{aligned}
& V_{c}=\pi(p f(l)-\tau)+\beta\left\{\pi V^{H}+(1-\pi) V^{L}\right\} \\
& \tau \leq \beta\left(V^{H}-V^{L}\right), \\
& \tau \leq p f(l) \\
& V^{H} \leq \bar{V} \\
& V^{L} \leq \bar{V} \\
& l, \tau, V^{H}, V^{L} \geq 0 .
\end{aligned}
$$

Here the state variable is $V_{c}$, the value entitlement to the entrepreneur at the continuation stage of a period. $l$ is the amount of labor the firm hires with funds from the bank. $\tau$ is 
the repayment to the bank if a high production shock is reported. $V^{H}$ and $V^{L}$ are the continuation value entitlements to the entrepreneur at the beginning of next period if she reports a high or a low shock respectively. Eq. (9) is the promising-keeping constraint. Eq. (10) is the short version of the incentive compatibility constraint

$$
p f(l)-\tau+\beta V^{H} \geq p f(l)+\beta V^{L} .
$$

This constraint ensures that the entrepreneur truthfully reports when a high shock is realized. Note that the entrepreneur cannot misreport when a low shock is realized. Eq. (11) is the limited liability constraint for the entrepreneur. Eq. (12) and (13) are imposed to ensure that the limited commitment constraint for the bank is satisfied.

Given $p$ and $\bar{V}$, by standard argument of dynamic programming, one can show the existence and uniqueness of the value function $W(V ; p)$ and $\hat{W}\left(V_{c} ; p\right)$, and can also show that the policy functions $\alpha(V ; p), X(V ; p), V_{c}(V ; p), l\left(V_{c} ; p\right), \tau\left(V_{c} ; p\right), V^{H}\left(V_{c} ; p\right)$ and $V^{L}\left(V_{c} ; p\right)$ are single-valued and continuous.

The upper bound on feasible value entitlements, $\bar{V}$, which has been taken as given so far, must satisfy

$$
B_{[0, \bar{V}]}(\bar{V} ; p)=W_{[0, \bar{V}]}(\bar{V} ; p)-\bar{V}=0,
$$

where the subscript $[0, \bar{V}]$ is imposed to highlight the state space associated with the value functions. If $B_{[0, \bar{V}]}(\bar{V} ; p)<0$, the limited commitment constraint for the bank is violated. If $B_{[0, \bar{V}]}(\bar{V} ; p)>0$, then competition among banks would drive the bank to promise a higher value than $\bar{V}$, in which case $\bar{V}$ is not the highest possible value entitlement to the entrepreneur. Using this result, Lemma 1 proves the existence and uniqueness of $\bar{V}$.

Lemma 1 For a given $p>0$, there exists a unique upper bound on feasible value entitlement to an entrepreneur, $\bar{V}(p)$.

PROOF: See Appendix B.

The following Lemmas and Propositions characterize the features of the optimal contract. Consider problem $\left(P_{1}\right)$ first. As in $\mathrm{C}-\mathrm{H}(2006)$, there exists a stochastic liquidation region, $\left[0, V_{r}\right]$, where $0<V_{r} \leq \bar{V}^{6}$. For values $V \in\left[0, V_{r}\right]$, it is optimal to give the entrepreneur a lottery with values of $X=0$ in case of liquidation and $V_{c}=V_{r}$ in case of continuation. The probability of liquidation, $\alpha(V)$ is decreasing in the entrepreneur's value entitlement. The total value of the contract in this region is given by a linear combination of $S$ and $\hat{W}\left(V_{r} ; p\right)$, with weights $\alpha(V)$ and $1-\alpha(V)$ respectively. These results are summarized in Proposition 1 .

Proposition 1 There exists $0<V_{r} \leq \bar{V}$, such that

(i) $\alpha(V)=1-\frac{V}{V_{r}}$ for $V \in\left[0, V_{r}\right]$, and $\alpha(V)=0$ for $V \in\left[V_{r}, \bar{V}\right]$;

(ii) $X(V)=0$ for $V \in[0, \bar{V}]$;

(iii) $V_{c}(V)=V_{r}$ for $V \in\left[0, V_{r}\right]$, and $V_{c}(V)=V$ for $V \in\left[V_{r}, \bar{V}\right]$;

(iv) $W(V)=S+\frac{\hat{W}\left(V_{r} ; p\right)-S}{V_{r}} V$, for $V \in\left[0, V_{r}\right]$, and $W(V ; p)=\hat{W}(V ; p)$ for $V \in\left[V_{r}, \bar{V}\right]$.

\footnotetext{
${ }^{6}$ Actually, $V_{r}<\bar{V}$, which will be established in Lemma 3 .
} 
Now consider problem $\left(P_{2}\right)$. By Proposition 1 (iii), the state variable $V_{c}$ lies in $\left[V_{r}, \bar{V}\right]$ in equilibrium. But we consider a larger space $[0, \bar{V}]$ for $V_{c}$ to establish the results. Since $f$ is strictly concave, it's not hard to establish the following result.

Proposition $2 \hat{W}\left(V_{c}\right)$ is strictly increasing and strictly concave for $V_{c} \in[0, \bar{V}]$. And $W(V ; p)$ is linearly increasing for $V \in\left[0, V_{r}\right]$ and strictly increasing and strictly concave for $V \in\left[V_{r}, \bar{V}\right]$.

For a given $V_{c} \in[0, \bar{V}]$, if the limited commitment constraints (12) and (13) are not binding, the continuation problem $\left(P_{2}\right)$ would be essentially the same as that of $\mathrm{C}-\mathrm{H}(2006)$ and shares similar properties. The following Lemma defines such a region.

Lemma 2 There exists $0<V_{1} \leq \bar{V}$, such that $V^{H}\left(V_{1}\right)=\bar{V}$. For any $V_{c}<V_{1}, V^{H}\left(V_{c}\right)<\bar{V}$ and $V^{L}\left(V_{c}\right)<\bar{V}$.

PROOF: See Appendix B.

It can be shown that $V_{r}<V_{1}<\bar{V}$. This relationship is established after we characterize the contract for $V_{c} \in\left[0, V_{1}\right]$. Basically, since the limited commitment constraints are not binding on this region, the contract shares same features as those of $\mathrm{C}-\mathrm{H}(2006)$ : the entrepreneur is borrowing constrained, transfers all revenues to the bank and consumes nothing (zero dividends).

Proposition 3 For $V_{c} \in\left[0, V_{1}\right]$,

(i) the limited liability constraint (11) is binding;

(ii) the incentive compatibility constraint (10) is binding;

(iii) $l\left(V_{c}\right)<l^{\star}(p)$;

(iv) $V^{L}\left(V_{c}\right)<V_{c}<V^{H}\left(V_{c}\right)$ as long as $V_{c}>0, V^{H}\left(V_{c}\right)$ is strictly increasing and $V^{L}\left(V_{c}\right)$ is non-decreasing;

PROOF: See Appendix B.

The repayment policy stated in Part (i) implies a zero dividend policy for the firm. This allows the equity value of the firm to reach its upper bound $\bar{V}$ in the shortest possible time. Part (iii) says that the firm is borrowing constrained in the sense that its employment is less than the unconstrained efficient level as defined in (1). This result follows from a binding incentive compatibility constraint. Part (iv) implies that the bank promises the entrepreneur a higher beginning-of-next-period value entitlement if a high shock is reported today, and a lower value entitlement if a low shock is reported today. Such report-dependent future value entitlements are crucial for inducing a truthful report from the entrepreneur. Since $V^{H}$ is less than $\bar{V}$ on this region, it is strictly increasing. $V^{L}$ is nondecreasing. Furthermore, since $V^{L}$ is bounded below by zero, there might exist a region of $V_{c}$ where $V^{L}$ is zero.

The following lemma states the relationship between $V_{r}, V_{1}$ and $\bar{V}$.

Lemma $3 V_{r}<V_{1}<\bar{V}$.

PROOF: See Appendix B. 
For $V>V_{1}$, the limited commitment constraint in a good state (12) becomes binding. So the contracting problem exhibits different features, which are summarized in the following proposition.

Proposition 4 For $V_{c} \in\left[V_{1}, \bar{V}\right]$,

(i) $V^{H}\left(V_{c}\right)=\bar{V}$, i.e., the limited commit constraint (12) is binding;

(ii) the incentive compatibility constraint (10) is binding;

(iii) $l\left(V_{c}\right)<l^{\star}(p)$;

(iv) $V^{L}\left(V_{c}\right)<V_{c}$, and $V^{L}\left(V_{c}\right)$ is strictly increasing in $V_{c}$;

(v) $\tau\left(V_{c}\right)>0$ and strictly decreasing in $V_{c}$;

(vi) there exists $\hat{V} \in\left[V_{1}, \beta \bar{V}\right)^{7}$ such that for $V_{c} \in\left[V_{1}, \hat{V}\right]$, the limited liability constraint (11) is binding; for $V_{c} \in(\hat{V}, \bar{V}],(11)$ is not binding, and $l\left(V_{c}\right)$ is strictly increasing.

PROOF: See Appendix B.

Part (i) actually establishes that the limited commitment constraint (12) is binding for $V_{c}>V_{1}$. Part (ii) and (iii) show that the incentive compatibility constraint is still binding and as a result borrowing is constrained. Part (iv) is the most crucial result for generating steady state firm exit and job reallocation. Without the limited commitment commitment for the bank, as in C-H (2006), when $V$ reaches the threshold $\tilde{V}(p)$, we would have $V^{H}(\tilde{V}(p)) \geq \tilde{V}(p)$ and $V^{L}(\tilde{V}(p))=\tilde{V}(p)$. This implies that once a firm's equity value reaches $\tilde{V}(p)$, it will never fall down. As a result the firm ceases to be borrowing constrained and will never be liquidated $(\alpha(\tilde{V}(p))=0)$. Similarly as implied by the Clementi and Hopenhayn contract, the evolution process of equity values would have two absorbing states, $V=0$ and $V \geq \tilde{V}(p)$. "Eventually, either the first one is reached and the firm is liquidated, or the second one is reached and borrowing constraints cease forever", as wrote in C-H(2006). If firms are financed by this type of contract, in a stationary industry equilibrium, all incumbent firms would reach the second state, where they employ the efficient amount of labor and produce at the efficient level in every period. There would be no job creation or destruction, and no firm entry or exit. With the limited commitment assumption, however, part (iv) together with (iv) of Proposition 3 shows that $V^{L}\left(V_{c}\right)<V_{c}$ for all feasible values of $V_{c}$, including the highest value $\bar{V}$. So starting from any level, the equity value of a firm can fall down to the liquidation region following a sequence of bad shock realizations. In other words, a firm faces a positive liquidation probability from the perspective of any stage of its life. It is this feature that generates endogenous firm exit, firm heterogeneity and job reallocation in the stationary industry equilibrium to be described next.

Part (v) and (vi) imply different repayment and dividend policies from $\mathrm{C}-\mathrm{H}(2006)$, where the firm transfers all the revenues to the bank and pays zero dividends until its equity value reaches the unconstrained efficient level $(\tilde{V}(p)$ in our context) and thereafter the firm

\footnotetext{
${ }^{7}$ There is no simple analytical result for the value of $\hat{V}$. Computation shows that it is very close to $V_{1}$ under various parameterizations.
} 
pays nothing back to the bank and all revenues are paid as dividends. Here, for $V_{c}>\hat{V}$, $d\left(V_{c}\right) \equiv p f\left(l\left(V_{c}\right)\right)-\tau\left(V_{c}\right)>0$, and $d\left(V_{c}\right)$ is strictly increasing since $l\left(V_{c}\right)$ is strictly increasing and $\tau\left(V_{c}\right)$ is strictly decreasing. So as its equity value reaches $\hat{V}$, the firm ceases to transfer all revenues to the bank and begins to pay dividends in a good state and the amount of dividends is strictly increasing in the firm's equity value. This seems a more realistic dividend policy than implied by the Clementi and Hopenhayn contract.

The optimal contract is solved numerically (see Appendix B for the solution method) and figures 1-6 of Appendix A plot the value functions and the policy functions for the baseline calibration to be described later. Among the features of the optimal contract, a notable one is the endogenous borrowing constraint: employment is strictly less than its unconstrained efficient level for all feasible equity values. Even though monotonicity of employment does not hold throughout the whole range of equity values, a firm with large equity values tends to employ more workers (see Fig. 5). In other words, the endogenous financing constraints tend to relax as the firm's equity value grows. This feature combined with the evolution dynamics of equity values drives the job reallocation process. If a firm receives a high production shock this period, its equity value for next period will increase, which would dictate more employment for next period (except in the small decreasing regions), i.e., the firm will create jobs. On the contrary, if a firm receives a bad shock, its equity value for next period will decrease, which would dictate the firm to lay off workers. If the equity value falls to the liquidation region, the firm may be liquidated and exit the industry. In both cases, the firm destroys jobs. Such job creation and destruction is an ongoing process during a firm's life cycle, since the optimal contract dictates that a firm never reaches a stage where such process stops until the firm is liquidated.

\subsection{Entry of New Firms}

In every period, new born entrepreneurs are offered lifetime contracts by banks and may accept whatever contracts give them the highest expected discounted value. In equilibrium they are offered the same contract ex-ante, which is the optimal contract characterized previously. If an entrepreneur accepts the contract, her project gets financed and a new firm enters the industry. Because of competition among banks, the value entitlement to an entrepreneur upon entry or the initial equity value of a new firm, $V_{0}$, is determined by

$$
\begin{array}{ll}
\left(P_{3}\right) \max _{V_{0} \in[0, \bar{V}(p)]} V_{0} \\
\text { s.t. } & \hat{B}\left(V_{0} ; p\right) \equiv \hat{W}\left(V_{0} ; p\right)-V_{0} \geq I-M,
\end{array}
$$

where (14) is the participation constraint for the bank. For a given $p$, if a solution to $\left(P_{3}\right)$ does not exist, the project is not financially feasible. Since $\hat{W}(\cdot ; p)$ is concave and $\hat{B}(0 ; p)=\beta S<I-M, \hat{B}(V ; p)$ is hump-shaped, as shown in Fig. 7. Notice that there exists a region of $V$ such that the value of the contract to the bank increases with the value of the contract to the firm, so both parties would find it beneficial to renegotiate the contract once the firm's equity value evolves to this region. Therefore the contract is not renegotiation-proof ${ }^{8}$.

\footnotetext{
${ }^{8}$ Renegotiation-proof contracts with repeated moral hazard are studied in Wang (2000) and Quadrini (2004), where renegotiation-proofness is obtained by imposing some lower bound on attainable expected
} 
Denote the solution to $\left(P_{3}\right)$ as $V_{0}(p)$. Then (14) is binding at $V_{0}(p)$, i.e., there is no gain to the bank by entering the contractual relationship with an entrepreneur. Once the initial equity value $V_{0}(p)$ is determined, the evolution of a new firm's equity value is completely dictated by the contract in relation to its production shock realizations. The firm simply follows the contract for its decisions on employment, repayments, dividends, and whether to exit or not.

The following lemma establishes the dependence of $V_{0}(p)$ on the output price $p$. It is to be used for establishing the existence and uniqueness of a stationary equilibrium with entry and exit.

Lemma $4 V_{0}(p)$ is continuous and strictly increasing in $p$. PROOF: See Appendix B.

\subsection{Evolution of the Industry}

As shown in the characterization of the optimal contract, the state of an incumbent firm is fully described by its equity value at the continuation stage of a period, $V_{c}$. So the state of the industry can be described by the distribution of all incumbent firms over $V_{c}$. The state of the industry can also be described by the distribution of firms over equity values at the beginning of a period. The former is chosen for simplicity since it is the distribution directly related to aggregate production. Let $\mu_{t}\left(V_{c} ; p\right)$ denote the distribution of incumbent firms over equity values at the continuation stage of period $t$, and denote the total mass of new entrant firms at the beginning of period t by $E_{t}$. Then $\mu$ satisfies the law of motion

$$
\begin{aligned}
\mu_{t+1} & (A ; p)=\int\left\{\pi\left(1-\alpha\left(V^{H}(V)\right)\right) \chi_{A}\left(V_{c}\left(V^{H}(V)\right)\right)\right. \\
& \left.+(1-\pi)\left(1-\alpha\left(V^{L}(V)\right)\right) \chi_{A}\left(V_{c}\left(V^{L}(V)\right)\right)\right\} \mu_{t}(d V ; p) \\
& +E_{t+1} \chi_{A}\left(V_{0}(p)\right)
\end{aligned}
$$

for $\forall A \in \mathcal{V}(p)$, where $\mathcal{V}(p)$ is the $\sigma$-algebra generated by the state space $[0, \bar{V}(p)] . \chi_{A}(\cdot)$ is an indicator function, i.e., $\chi_{A}(V)$ equals 1 if $V \in A$ and equals 0 otherwise.

The transition from $\mu_{t}$ to $\mu_{t+1}$ can be written as $\mu_{t+1}=T^{\star}\left(\mu_{t}, E_{t+1} ; p\right)$. It can be shown that $T^{\star}$ is linearly homogeneous in $\mu$ and $E$ jointly. That is, if the industry has twice as many firms of each type at the continuation stage of period $t$, and entry is doubled at the beginning of period $t+1$, then the industry will end up with twice as many firms of each type at the continuation stage of period $t+1$. This property turns to be useful in the computation of an invariant distribution (see Appendix B). Proposition 5 established this result.

Proposition $5 T^{\star}$ is linearly homogeneous in $\mu$ and $E$ jointly. PROOF: See Appendix B.

With a measure of firms, $\mu$, total labor demand $L^{D}$, output $Y$, repayment to the bank

utilities of the agent. 
$T$, dividends $\Pi$, and total scrap value of liquidated firms $R$ can be defined respectively.

$$
\begin{aligned}
& L^{D}(\mu ; p)= \int l(V ; p) \mu(d V ; p), \\
& Y(\mu ; p)= \pi \int f(l(V ; p)) \mu(d V ; p), \\
& T(\mu ; p)=\pi \int \tau(V ; p) \mu(d V ; p), \\
& \Pi(\mu ; p)=p Y(\mu ; p)-T(\mu ; p), \\
& R(\mu ; p)=\int\left\{\pi \alpha\left(V^{H}(V ; p)\right)+\right. \\
&\left.(1-\pi) \alpha\left(V^{L}(V ; p)\right)\right\} S \mu(d V ; p) .
\end{aligned}
$$

It follows from Proposition 5 that the aggregate quantities defined above are linearly homogeneous in $\mu$.

\subsection{Balance Sheet of the bank}

In the model banks are assumed to be competitive. They participate in the long-term credit market in which they provide funds for entrepreneurs in exchange for payments. They also have access to an external short-term (one-period) credit market, where they can borrow or lend at interest rate $r$. Depending on their performance in the long-term credit market, some banks may borrow and others may lend funds in the short-term credit market to balance their budgets. It's interesting to know the total amount of short-term funds banks as a whole would hold in equilibrium. Summarizing the banks into a single agent, this quantity can be derived from the balance sheet.

Suppose at the beginning of period $t$, the bank holds short-term funds, $F_{t}$, which are raised in the short-term credit market at the end of last period. Some firms are liquidated, and the bank receives total scrap value $R_{t}$. These funds are used for financing the initial investment costs of new entry firms and the labor costs of all incumbent firms. After production, the bank receives total payment $T_{t}$ from incumbent firms. Finally, the bank pays back $F_{t}$ with interests, and borrows or lends new funds $F_{t+1}$ in the re-opened short-term credit market. Therefore her balance sheet for period $t$ is given by

$$
F_{t+1}+R_{t}+T_{t}=E_{t}(I-M)+L_{t}^{D}+(1+r) F_{t} .
$$

\subsection{Stationary Competitive Equilibrium}

A stationary competitive equilibrium for the industry consists of an output price $p^{\star} \geq 0$ and total output $Q^{\star}$; policy functions $\alpha\left(V ; p^{\star}\right), X(V ; p), V_{c}\left(V ; p^{\star}\right), l\left(V_{c} ; p^{\star}\right), V^{H}\left(V_{c} ; p^{\star}\right)$, $V^{L}\left(V_{c} ; p^{\star}\right), \tau\left(V_{c} ; p^{\star}\right)$, as well as value functions $W\left(V ; p^{\star}\right)$ and $\hat{W}\left(V_{c} ; p^{\star}\right)$; a measure of incumbent firms $\mu^{\star}$ and a mass of entrants $E^{\star} \geq 0$; aggregate quantities $Y\left(\mu^{\star} ; p^{\star}\right), L^{D}\left(\mu^{\star} ; p^{\star}\right)$, $T\left(\mu^{\star} ; p^{\star}\right), \Pi\left(\mu^{\star} ; p^{\star}\right)$ and $R\left(\mu^{\star} ; p^{\star}\right)$; and bank short-term credit $F^{\star}$ such that

(i) the value functions and policy functions solve $\left(P_{1}\right)$ and $\left(P_{2}\right)$; 
(ii) $p^{\star}=D\left(Q^{\star}\right)$, and $Q^{\star}=Y\left(\mu^{\star} ; p^{\star}\right)$;

(iii) $V_{0}\left(p^{\star}\right) \leq M$ solves $\left(P_{3}\right)$, with equality if $E^{\star}>0$;

(iv) $\mu_{t} \equiv \mu^{\star}$ and $E_{t} \equiv E^{\star}$ solve Eq. (15);

(v) $R\left(\mu^{\star} ; p^{\star}\right)+T\left(\mu^{\star} ; p^{\star}\right)=E^{\star}(I-M)+L^{D}\left(\mu^{\star} ; p^{\star}\right)+r F^{\star}$.

Condition (ii) states that demand must equal supply in the output market. Condition (iii) is the free entry condition for firms. Since there is unlimited supply of potential entrants, $V_{0}\left(p^{\star}\right)$ cannot be strictly bigger than the initial wealth of an entrepreneur, $M$. If $E^{\star}$ is strictly positive, $V_{0}\left(p^{\star}\right)$ must equal $M$ to ensure that firms are willing to enter. In this case, since (14) is binding at $V_{0}\left(p^{\star}\right)$, then

$$
\hat{W}\left(M ; p^{\star}\right)=I \text {. }
$$

This condition says that the total expected discounted value from undertaking the project equals the initial setup cost of the project, or in other words the total expected value from entering equals the total entry cost. It is used to pin down $p^{\star}$ in a stationary equilibrium with positive entry. Condition (iv) states that $\mu^{\star}$ and $E^{\star}$ are such that the state of the industry is reproduced in every period through the optimal actions of firms and banks. Finally condition (v) states that the aggregate quantities satisfy the balance sheet of the bank.

It follows from the definition that the stationary equilibrium may take two different forms: with entry and exit or without. Since the data used to calibrate the model in a later section exhibits significant amount of entry and exit, an equilibrium with entry and exit is of greater interest. The industry evolution model of Hopenhayn (1992) has the property that if the entry cost is less than a critical value, there exists an equilibrium with entry and exit, and it is the unique stationary equilibrium. A similar property is established in Theorem 1.

Theorem 1 There exists $I^{\star}>0, M^{\star}>0$ such that for $I<I^{\star}$ and $M \geq M^{\star}$ a stationary equilibrium with entry and exit exists and it is the unique stationary equilibrium for the industry.

PROOF: See Appendix B.

Intuitively, if the entry cost $I$ is not too big, undertaking the project would be profitable. If a firm's initial wealth $M$ is not too small, or equivalently, if the part of the entry cost undertaken by the bank is not too big, a contractual relationship between a firm and the bank would be feasible. The bank would like to offer contracts and firms would like to accept the contracts and enter the industry. As long as there are some firms in the industry, there is always firm entry and exit because the optimal contract predicts that a firm has a positive probability of being liquidated at any stage of its life. This property also ensures that the mixing condition required for convergence of the firm distribution is satisfied.

\section{Quantitative Analysis}

In this section, the model laid out in the last two sections is solved numerically. An algorithm for finding the stationary equilibrium with entry and exit is provided in Appendix B. The stationary equilibrium has the property that aggregate variables are constant over time while 
individual firms are continually adjusting over time. At any point in time there are some firms expanding, some firms contracting, some entering while others exiting. Entering and expanding firms hire workers and create jobs, while contracting and exiting firms fire workers and destroy jobs. On the contrary, the equilibrium with symmetric information has no such dynamics at all, as discussed in Section 3.1. This provides the setting in which the questions outlined in the Introduction can be addressed.

\subsection{Baseline Calibration}

To execute a quantitative analysis, we need to specify functional forms and assign parameter values. The production function is assumed to take the form

$$
f(l)=A l^{\gamma}
$$

where $0<\gamma<1$, and $A$ is a scale factor. The inverse demand function takes the form

$$
p=D(Q)=\frac{1}{a Q}
$$

where $a$ is a positive constant.

Assume that a period is one year. The interest rate $r$ is set to 6.5 percent, the average annual real interest rate of the U.S. over the last century, and $\beta=\frac{1}{1.065}$. $\gamma$ is set to 0.64 , the average labor share of income over the postwar period. The assignment of remaining parameters requires a value of the stationary equilibrium output price $p^{\star}$. Following Hopenhayn and Rogerson (1993), $p^{\star}$ is normalized to unity and values of remaining parameters are chosen to be consistent with it. The scale factor $A$ is chosen such that the unconstrained efficient level of employment is 1500 workers $^{9}$.

The probability of realizing a good production shock $\pi$, scrap value $S$ and entrepreneur's initial wealth (a new firm's initial equity value) $M$ are crucial for the entry and exit behavior of the model. They are chosen to match three moments of the U.S. manufacturing data. The first one is the mean annual exit rate of manufacturing firms due to bankruptcy and liquidation. According to Dunne, Roberts and Samuelson (1988), the exit rate of manufacturing firms during a 5-year period is 35.2 percent on average during the period of 1963 to 1982, implying a mean annual exit rate of 7 percent. Because firms may exit due to a lot of forces and the model formulated here only considers one driving force-financing problems, calibrating the model to match a 7 percent exit rate would over estimate the quantitative significance of the financial frictions for job reallocation ${ }^{10}$. The lack of data and relevant empirical studies prevents us from obtaining an accurate measure of the exit rate due to bankruptcy and liquidation. Fortunately Compustat data records the year and reasons of deletion of a firm from Compustat, which allows us to compute the mean annual exit rate

\footnotetext{
${ }^{9}$ we tried other values of efficient employment, such as 1000 and 2000 workers, and found that the results are not sensitive to this amount.

${ }^{10} \mathrm{In}$ an earlier version of the paper, we calibrate the model to match a 4.5 percent of new firm entry rate (according to Dunne, Roberts and Samuelson (1988)) and a 2.17 percent of employment shares of exiting plants (computed using job creation and destruction data available on John Haltiwanger's website) and the model generates a 6.45 percent of job creation or destruction rate.
} 
of Compustat manufacturing firms due to bankruptcy and liquidation. This number is 0.31 percent for the period of 1973 to $1988^{11}$. This measure provides a lower bound to the exit rate of all manufacturing firms due to bankruptcy and liquidation during this period, since Compustat firms are typically large and larger firms tend to have lower bankruptcy and liquidation rates. The second moment is the mean annual employment share of exiting manufacturing firms. Again, using the Compustat data we obtain a lower bound of this moment for the period of 1972 to $1988,0.05$ percent. This measure is much lower than the mean annual employment share of exiting plants, which is 2.34 percent according to Davis, et al. (1996). The last moment is the relative size of exiting firms due to bankruptcy and liquidation. Dunne, et al. (1988) defined the relative size of exiting firms as the ratio of average output of exiting firms to the average output of non exiting firms, and estimated it to be 0.34 on average during the period of 1967 to 1982 . Since there is no evidence that shows systematic size difference between exiting firms due to bankruptcy and exiting firms due to other reasons, we take this number as the measure of the third moment. Computation shows that there is a unique choice of $\pi, S$ and $M$ that matches these three moments.

Once $M$ is chosen, simply set $I=\hat{W}\left(M ; p^{\star}\right)$. Recall that this condition has to be satisfied in an equilibrium with positive entry. Finally, the scale parameter $a$ in the inverse demand function is set such that the total employment in the stationary equilibrium equals the mean annual employment of the manufacturing industry during 1972 and 1988, 18,135,000 employees according to the Annual Survey of Manufactures (ASM).

Table 1 summarizes the baseline parameter values and matched quantities. In particular, $\pi=0.51^{12}$. To see whether the model's predictions are sensitive to $\pi$, other values of $\pi$ are considered, and we find that the main results are not sensitive to this parameter choice once other parameters of the model are re-calibrated to match the three moments. This will be discussed more in later sections.

\subsection{Quantitative Significance of Job Reallocation due to Financing Constraints}

With parameter values determined, the equilibrium is numerically solved. The symmetric information equilibrium is also solved by following the descriptions of Section 3.1, taking as given all the parameter values in Table 1. Table 2 in Appendix A presents the summary statistics for both equilibria. Note that the job creation and destruction rate in the stationary equilibrium with financial frictions is 4.75 percent per year, implying an annual job reallocation rate of 9.5 percent, while its frictionless counterpart is zero (see the third panel of Table 2). According to Davis, et al (1996), where the ASM is exploited to document job creation and destruction statistics, the mean annual job creation rate of U.S. manufacturing is 9.1 percent and job destruction rate is 10.3 percent during the 1972-1988 periods. So

\footnotetext{
${ }^{11}$ We want to compare the model predictions to those reported in Davis, et al. (1996), where the Annual Survey of Manufactures (ASM) for the period of 1972 to 1988 is used to document job reallocation statistics.

${ }^{12} \mathrm{At}$ a first sight, this may imply extremely volatile profits since the firm's output is zero with a probability of 0.49. Our understanding is that first the zero output is just a normalization for simplicity and shouldn't be taken as "no output at all". Second, once a lower $\beta$ is considered, which is not unreasonable since firms discount future more heavily than households, a much higher $\pi$ is obtained to match the three moments while the model's main results are not affected. For instance, for $\beta=\frac{1}{1.075}$, the estimate of $\pi$ is 0.58 .
} 
Table 1: Baseline Calibration

\begin{tabular}{lrr}
\hline & Parameter & Value \\
\hline Discount factor & $\beta$ & 0.939 \\
Interest rate of short-term funds & $r$ & 0.065 \\
Probability of a good production shock & $\pi$ & 0.51 \\
Labor share & $\gamma$ & 0.64 \\
Scale factor in production function & $A$ & 42.62 \\
Scrap value & $S$ & 4,460 \\
Entrepreneur's initial wealth & $M$ & 3,254 \\
Initial investment of a project & $I$ & 10,478 \\
Scale factor in demand function & $a$ & $3.25 \cdot 10^{-8}$ \\
\hline \hline Matched quantities & Target & Model \\
\hline Exit rate of firms & $0.31 \%$ & $0.31 \%$ \\
Employment share of exiting firms & $0.05 \%$ & $0.05 \%$ \\
Relative size of exiting firms & 0.34 & 0.33 \\
Total employment of industry & $1.8135 \cdot 10^{7}$ & $1.8135 \cdot 10^{7}$ \\
\hline
\end{tabular}

conditional on the model 51.1 percent of job creation, 46.1 percent of job destruction and 49 percent of job reallocation observed in the data can be accounted for by the financial frictions in the model. To check the robustness of this result, we considered various parameterization and the model always generates a lot of job reallocation. For instance, for $\pi=0.55$, the job creation or destruction rate is 4.82 percent. It suggests that if financial frictions are as severe as assumed in the model, they could potentially have significant impact on job reallocation. On the other hand, this result may over estimate the effect since the private information problem is probably more applicable to smaller firms while smaller firms have higher job creation and destruction rates.

According to ASM, a large fraction of job creation and destruction is accounted for by start-up (15.5\%) and shut-down plants (22.9\%) despite the employment shares of startups and shutdowns are relatively small. Since we calibrate the model to match a very low exit rate, the job creation and destruction shares of entrants and exiters are much smaller, 2.52 and 1.16 percent respectively. But they are relatively big compared to the employment shares of entrants and exiters, which are 0.12 and 0.05 percent respectively. This property is consistent with the data.

\subsection{Negative Size Dependence of the Turnover}

As described in the Introduction, the turnover of firms and jobs in the data exhibits a negative dependence on firm size and age. In the model, the turnover of firms and jobs is driven by the endogenous financing constraints due to the asymmetric information and limited commitment problems in firm financing. It's interesting to know whether the turnover exhibits similar properties, and if so, how close they are to those observed in the data. To explore these questions, we draw 100,000 firms from the stationary firm distribution over equity values (Fig. 8 plots the distribution), and simulate them for 170 periods (10 
simulations of 17 periods). For each simulation, firm exit rates and mean annual job flow rates are computed for each size and age category. The figures reported in Table 3-9 are averages across the 10 simulations.

\subsubsection{Exit Rates by Size}

Table 3 reports the 1-year, 2-year, 5-year, 10-year and 15-year exit rates for each firm size category, where Classification we gives a broad firm size classification and Classification II is a more detailed one. Firm size here refers to employment in the base year, i.e. the initial year of the time interval over which a particular exit rate is calculated. Table 3 displays a strong negative relationship between firm exit rates and the size of firms. For example, 50 percent of firms with employment less than 300 workers exit in 10 years, while only 3 percent of firms with employment between 700 and 799 workers exit in 10 years. In particular, the 10-year and 15-year exit rates are strictly decreasing as the size of firms increases.

The driving force underlying the negative size dependence is a negative relationship between liquidation probabilities and firm equity values and an overall positive relationship between equity values and employment.

\subsubsection{Employment Flows by Size}

Several related but distinct concepts of employer size have been adopted by empirical studies in computing job flow rates and classifying firms or plants. A traditional measure (see Dunne, Roberts and Samuelson (1989) and Evans (1987)) is base year employment. Using this measure, job creation rates for new firms are not well defined. Davis et al. (1996) argue that the base year size concept is subject to several other defects, and instead propose two new concepts for plant size: current plant size and average plant size. Despite different size concepts adopted, the empirical studies all find a negative size dependence of job flow rates. Following Davis et al. (1996), we define current firm size and average firm size, where current firm size equals the simple average of a firm's current employment and its employment 1 year ago and average firm size equals the weighted mean annual employment over the life cycle of the firm. Our analysis considers the three concepts of firm size. Specifically, to explore the relationship between job flow rates and base year size, job flow rates are defined using base year employment and firms are classified by their base year employment ${ }^{13}$. To explore the relationship between job flow rates and current firm size or average firm size, job flow rates are defined using current firm size, and firms are classified by their current size or average $\operatorname{size}^{14}$. This is consistent with the practice in Davis et al. (1996), despite the production units considered here are firms rather than plants.

Table 4 reports the correlation coefficients between job flow rates and firm size for the three size measures. Note that all the figures are significantly less than zero, implying a strong negative correlation of job flow rates with firm size. In particular, the correlation coefficients of job creation rates, job destructions rates and job reallocation rates (sum of

\footnotetext{
${ }^{13}$ For example, job creation rate from t-1 to $\mathrm{t}$ for a firm is defined as the ratio of employment gains to the firm's employment in t-1.

${ }^{14}$ For example, job destruction rate from t- 1 to $t$ for a firm is defined as the ratio of employment losses to the firm's average employment of $\mathrm{t}-1$ and $\mathrm{t}$.
} 
creation rates and destruction rates) with average firm size are $-0.5073,-0.5273,-0.5105$ respectively. These figures are very close to those in the ASM data, which are approximately $-0.626,-0.5433$ and -0.5882 respectively ${ }^{15}$. This result shows that the model can predict 81 percent of the negative size dependence for job creation, 97 percent for job destruction, and 87 percent for job reallocation. The negative size dependence is a robust finding as we vary parameter values. In particular, for $\pi=0.55$ (other parameters such as $\beta, S$ and $M$ are reset to match the three moments) the correlation coefficients of job flow rates with average firm size are $-0.49,-0.55$ and -0.52 respectively.

To further explore the size dependence of gross employment flows, we also report the mean annual job flow rates shares by firm size category in Table 5-7, where Table 5 is based on base year size, Table 6 current firm size, and Table 7 average firm size. Except for very small firms, job creation rates are monotonically decreasing with firm size. This pattern is similar for the three measures of firm size. The weak positive relationship between job creation rates and firm size for small firms results from the non-monotonic labor policy function in low regions of equity values. Job destruction rates exhibit a more pronounced negative correlation with firm size in all three tables. In particular, job destruction rates are strictly decreasing with average firm size throughout the range of employment. Job reallocation rates also display a strong negative correlation with firm size. In terms of net growth rates of employment, Table 5-7 do not show systematic correlation between them and firm size. This finding is also consistent with Davis et al. (1996).

Table 8 is obtained by combining Table 4.1 and 4.3 in Davis, et al (1996). It displays the job flow rates by a crude classification of average firm size for ASM. Even though the small, medium and large firms are classified differently, a comparison between Table 7 and Table 8 gives some further information on how well the model matches the data. It shows that the magnitudes of job flow rates for each size category are compatible to their data counterparts. But the model predicts higher job creation, destruction and reallocation rates than the data for small and medium firms, while lower rates for large firms, suggesting that financing contraints, as the only driving force for firm dynamics in the model, impact on smaller firms much more significantly than on large firms. As documented in the data, medium and large firms account for a majority of job creation and job destruction, despite of the higher creation and destruction rates among small firms. This property is more pronounced in the model due in the data.

\subsection{Exit Rates and Employment Flows by Age}

The model also generates an unconditional negative age dependence of firm exit and job reallocation. Table 9 reports firm exit rates and Table 10 reports job flow rates by the age

\footnotetext{
${ }^{15}$ These figures are computed using the third panel of Table 4.1 in Davis, et al (1996). The job flow rates reported there for each size category are weighted average plant-level job flow rates across those plants whose parent firms' average size are within that category. So even though the reported job flow rates are not the firm-level job flow rates for that average firm size category, they provide an upper bound to the firm-level job flow rates. Replacing each size category with its mid-point, then we have a group of values for average firm size and corresponding job flow rates so that a set of correlation coefficients between average firm size and job flow rates can be computed. We take these measures as an approximation to the true correlation coefficients between firm-level job flow rates and average firm size in the ASM data.
} 
of firms. Note that firm exit rates, job creation rates, destruction rates and reallocation rates are all decreasing with firm age. However, the negative age dependence results from the negative size dependence. Older firms are typically larger and larger firms have lower exit rates and job reallocation rates, therefore older firms have lower exit rates and job reallocation rates. Once firm size is controlled, the negative age dependence disappears.

\subsection{A Comparison between the Equilibria with and without Fi- nancial Frictions}

The model also has interesting implications of financial frictions in other aspects. Table 2 presents a comparison between the equilibria with and without the financial frictions, which gives us an understanding of the quantitative impacts of financial frictions on firm size distribution, aggregate output, employment, financial depth, and etc.

First, the financial frictions introduce variation to firm size distribution. In the frictionless world all firms have identical size, while with financial frictions there is a lot of heterogeneity, firm size ranging from 153 to 1,413 workers. Fig. 9 depicts the stationary distribution of firms over employment, which is derived from the stationary firm distribution over equity values. Note that the distribution is very skewed to the right, i.e., a majority of firms are large with employment more than 1,000 workers. While in the data, small firms account for a large fraction of total number of firms. Firm size distribution is also more dispersed in the data. The model's prediction for firm size distribution can be improved by adding heterogeneity into the production technology. The model abstracts from this to focus on the role of financial frictions.

Second, the total number of firms is less with financial frictions, while the average firm size is larger. In the model financing contraints relax as firms become larger, as a result the equilibrium favors a smaller number of firms with larger size. This observation seems to suggest that financial frictions also play a role in the determination of industry size and market structure.

Third, the presence of financial frictions can cause sizable losses in aggregate output and employment and considerable increases in output price. Compared to the frictionless world, the equilibrium output with frictions has decreased by 9.5 percent, employment decreased by 7.8 percent, and output price increased by 10.5 percent. This observation might justify the intensified exercise of government watchdog accounting procedures at the Securities and Exchange Commission, which aims to increase information transparency and eliminate the asymmetric information problem.

Fourth, the presence of financial frictions can greatly shift the division of revenues between banks and firms. The last panel of Table 2 reports the cash flow items in both equilibria. Note that with asymmetric information, the total payments to the bank are relatively lower (67.7 percent versus 88.8 percent of total revenues) while the total dividends of firms are relatively higher (32.3 percent versus 11.2 percent of total revenues). With informational asymmetries, the bank has to provide incentives for entrepreneurs to truthfully reveal their private information, which is achieved by giving relatively more to the entrepreneurs.

Finally, the total short-term liability held by the bank is 3 times less in the equilibrium with financial frictions. In a general equilibrium setting, this item would be the amount of 
funds that are intermediated through banks, which is an indicator of the financial depth. This result suggests that the presence of financial frictions may greatly hinder the development of financial market.

\subsection{Comparative Static Properties}

The discussions above show that informational asymmetries and limited commitment in firm financing causes inefficient firm exit and job reallocation, output loss, employment loss and rise in equilibrium output price. In this section, a comparative static analysis is implemented to see how these impacts vary with key primitives of the model. We consider the effects of changes in the discount factor, riskiness of projects, entry cost, and entrepreneurs' initial wealth. The results are summarized in Table 11. For each set of new parameterization, the equilibrium with financial frictions is resolved to find the first four items in each panel, where relative size of entrants and exiters are defined following the definition of Dunne, et al. $(1989)^{16}$. The frictionless equilibrium with same parameterization is also solved such that a comparison is made to find the last three items in each panel.

The first panel shows that the lower the discount factor, the higher the exit rate and job reallocation rate, and the larger the rise in output price and the losses in aggregate output and employment. This result suggests that increases in the interest rate worsen the adverse effects of the financial frictions. The second panel displays the effects of changes in project riskiness, which is measured by the probability of realizing a good shock. The lower $\pi$ is, the riskier the projects are. Panel two shows that increases in project riskiness lead to more firm exits, more job creation and destruction, and larger losses in output and employment. The third panel considers entry cost. Higher entry cost causes more job reallocation, more output and employment loss, and larger increases in output price. But the effect of entry cost on firm entry or exit rate is not monotonic. It depends on the relative magnitude of the scrap value $S$, firm's initial wealth $M$ and the entry cost $I$. Higher entry cost implies relatively smaller $S$ and $M$, while smaller $S$ decreases firm exits and smaller $M$ increases firm exits. The last panel displays the effects of changes in firms' initial wealth $M$. Higher $M$ reduces firm exits, job reallocation and losses in output and employment, i.e., more firm internal funds mitigates the adverse effects of financial frictions. This result is consistent with the literature on agency costs, such as Bernanke and Gertler (1989) and Gertler (1992), where a uniform finding is that higher net worth of firms moderates agency costs.

Another finding is how the relative size of entrants and exiters are affected by these key factors. The size determination of entrants and exiters has been an interesting issue in the Industry Organization literature. Table 11 shows that changes in interest rate and project riskiness have no significant effects on the relative size of entrants and exiters, while changes in entry cost and firm initial wealth do. Higher firm initial wealth leads to a larger relative size of both entrants and exiters. Lower entry cost implies relatively higher firm initial wealth and thus has same effects.

\footnotetext{
${ }^{16}$ Relative size of entrants $=\frac{\text { total output of entrants/number of entrants }}{\text { total output of incumbent firms/number of incumbent firms }}$
} 


\section{Conclusion}

Empirical evidence suggests that financing constraints may play an important role in the determination of firm dynamics. This paper constructs and calibrates an industry equilibrium model, in which firms' growth and failure are driven by endogenous financing constraints arising from asymmetric information and limited commitment problems in firm external financing, to explore the quantitative implications of financing constraints for job reallocation. It finds that endogenous financing constraints can account for a substantial amount of job reallocation and the negative size dependence of gross job flow rates. The paper contributes to the literature mainly in two aspects. First, it quantitatively evaluates the significance of financing constraints for job reallocation, which has not been emphasized in the literature. And to do so, it introduces limited commitment of banks into a dynamic contracting problem between a firm and a bank and show that it helps generate steady state firm entry, exit and job reallocation. This provides a theoretical contribution to existing literature on dynamic risk sharing and the literature on firm dynamics.

This exercise can be viewed as a first step toward the study of how financial market frictions affect gross job flows. For simplicity, the model abstracts from capital accumulation, technological progress, and aggregate uncertainty, all of which are closely related to employment decisions of firms. In the model, financial frictions affect employment flows directly through imposing constraints in the labor finance of firms. It would be interesting to study how financial frictions impact job flows through other channels. The model also suggests that financial frictions play a role in accounting for firm size distribution, industry size, market structure, output growth and etc. Each of them deserves further investigation. 


\section{References}

Aiyagari, S. R. and Williamson, S. D. (1999), "Credit in a Random Matching Model with Private Information", Review of Economic Dynamics 2, 36-64.

Albuquerque, R. and Hopenhayn, H. (2004), "Optimal Dynamic Lending Contracts with Imperfect Enforceability", Review of Economic Studies 71, 285-315.

Atkeson, A. and Lucas, R. (1995), "Efficiency and Inequality in a Simple Model of Efficient Unemployment Insurance", Journal of Economic Theory 66, 64-88.

Atkeson, A. and Lucas, R. (1992), "On Efficient Distribution With Private Information", Review of Economic Studies 59, 427-453.

Bernanke, B. and Gertler, M. (1989), "Agency Costs, Net Worth, and Business Fluctuations", The American Economic Review 79, 14-31.

Carlstrom, C. and Fuerst, T. S. (1997), "Agency Costs, Net Worth, and Business Fluctuations: A Computable General Equilibrium Analysis", The American Economic Review 87, 893-910.

Clementi, G. L. and Hopenhayn, H. (2006), "A Theory of Financing Constraints and Firm Dynamics", Quarterly Journal of Economics 121, 229-266.

Cooley, T. F. and Quadrini, V. (2001), "Financial Markets and Firm Dynamics", American Economic Review 91, 1286-1310.

Cooley, T. F. and Quadrini, V. (2004), "Aggregate Consequences of Limited Contract Enforceability", Journal of Political Economy 112, 817-847.

Davis, S. J., Haltiwanger, J. C. and Schuh, S. (1996), Job creation and destruction. Cambridge, The MIT Press.

Dunne, T., Roberts, M.J. and Samuelson, L. (1989), "The Growth and Failure of U.S. Manufacturing Plants", Quarterly Journal of Economics 104, 671-698.

Dunne, T., Roberts, M. J. and Samuelson, L. (1988), "Patterns of Firm Entry and Exit in U.S. Manufacturing Industries", Rand Journal of Economics 19, 495-515.

Evans, D. S. (1987), "The Relationship Between Firm Growth, Size and Age: Estimates for 100 Manufacturing Industries", The Journal of Industrial Economics 35, 567-581.

Fazzari, S., Hubbard, R. G. and Peterson, B. C. (1988), "Financing constraints and corporate investment." Brooking Papers on Economic Activity 1, 141-206.

Gertler, M. (1992), "Financial Capacity and Output Fluctuation in an Economy with MultiPeriod Financial Relationships", Review of Economic Studies 59, 455-472.

Gilchrist, S. and Himmelberg, C. P. (1995), "Evidence on the Role of Cash Flow for Investment", Journal of Monetary Economics 36, 541-572. 
Gollier, C., Koehl, P.-F., and Rochet, J.-C. (1997), "Risk Tading Behavior with Limited Liability and Risk Aversion", Journal of Risk and Insurance 64, 347-370.

Green, E. (1987), "Lending and the Smoothing of Uninsurable Income", In Contractual Arrangements for Intertemporal Trade. University of Minnesota Press, Minneapolis, MN.

Hall, B. H. (1987), "The Relationship Between Firm Size and Firm Growth in the U.S. Manufacturing", The Journal of Industrial Economics 35, 583-606.

Hopenhayn, H. (1992), "Entry, Exit and Firm Dynamics in Long Run Equilibrium", Econometrica 60, 1127-1150.

Hopenhayn, H., and Rogerson, R. (1993), "Job Turnover and Policy Evaluation: a General Equilibrium Analysis", Journal of Political Economy 101, 915-938.

Jovanovic, B. (1982), "Selection and the Evolution of Industry", Econometrica 50, 649-670.

Krueger, D., and Uhlig, H. (2006), "Competitive Risk Sharing Contracts with One-Sided Commitment", Journal of Monetary Economics, forthcoming.

Phelan, C. (1995), "Repeated Moral Hazard and One-Sided Commitment", Journal of Economic Theory 66, 488-506.

Quadrini, V. (2004), "Investment and Liquidation in Renegotiation-Proof Contracts with Moral Hazard", Journal of Monetary Economics 51, 713-751.

Repullo, R. (2004), "Capital requirements, market power, and risk-taking in banking", Journal of Financial Intermediation 13, 156-182.

Sinn, H.-W. (2001), "Risk Taking, Limited Liability and the Competition of Bank Regulators", NBER Working Papers, 8669.

Spear, S. E. and Srivastava, S. (1987), "On Repeated Moral Hazard With Discounting", Review of Economic Studies 54, 599-617.

Stokey, N. L., Lucas, R. E. Jr. and Prescott, E. C. (1989), Recursive methods in economic dynamics, Cambridge, MA: Harvard University Press.

Wang, C. (2000), "Renegotiation-Proof Dynamic Contracts with Private Information", Review of Economic Dynamics 3, 396-422.

Whited, T. (1992), "Debt, Liquidity Constraints, and Corporate Investment: Evidence from Panel Data", Journal of Finance, 47, 1425-1460. 


\section{APPENDIX A: Figures and Tables}
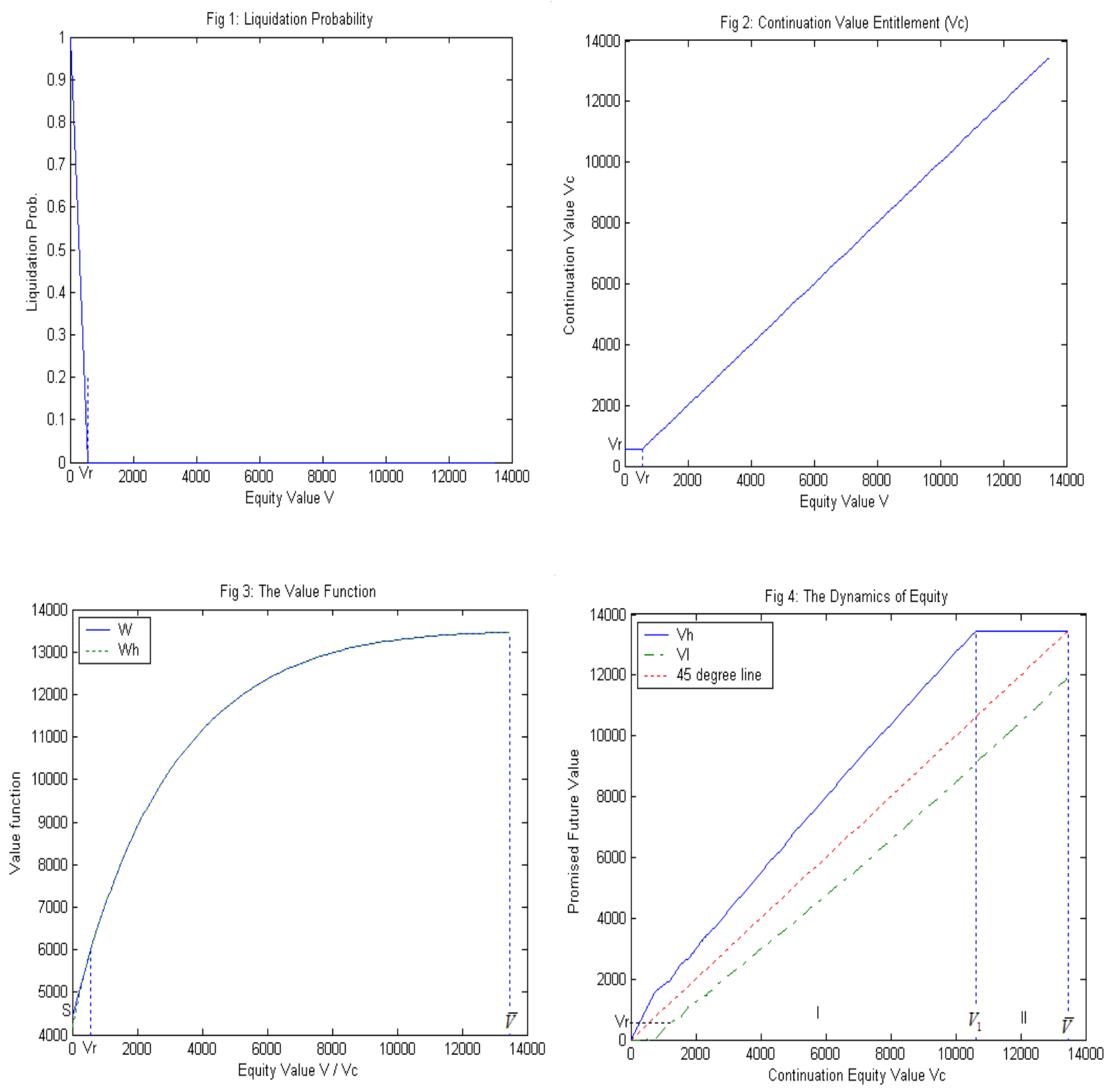

Notes: Region I denotes [0, $\left.V_{1}\right]$, and II, $\left[V_{1}, \bar{V}\right]$. 

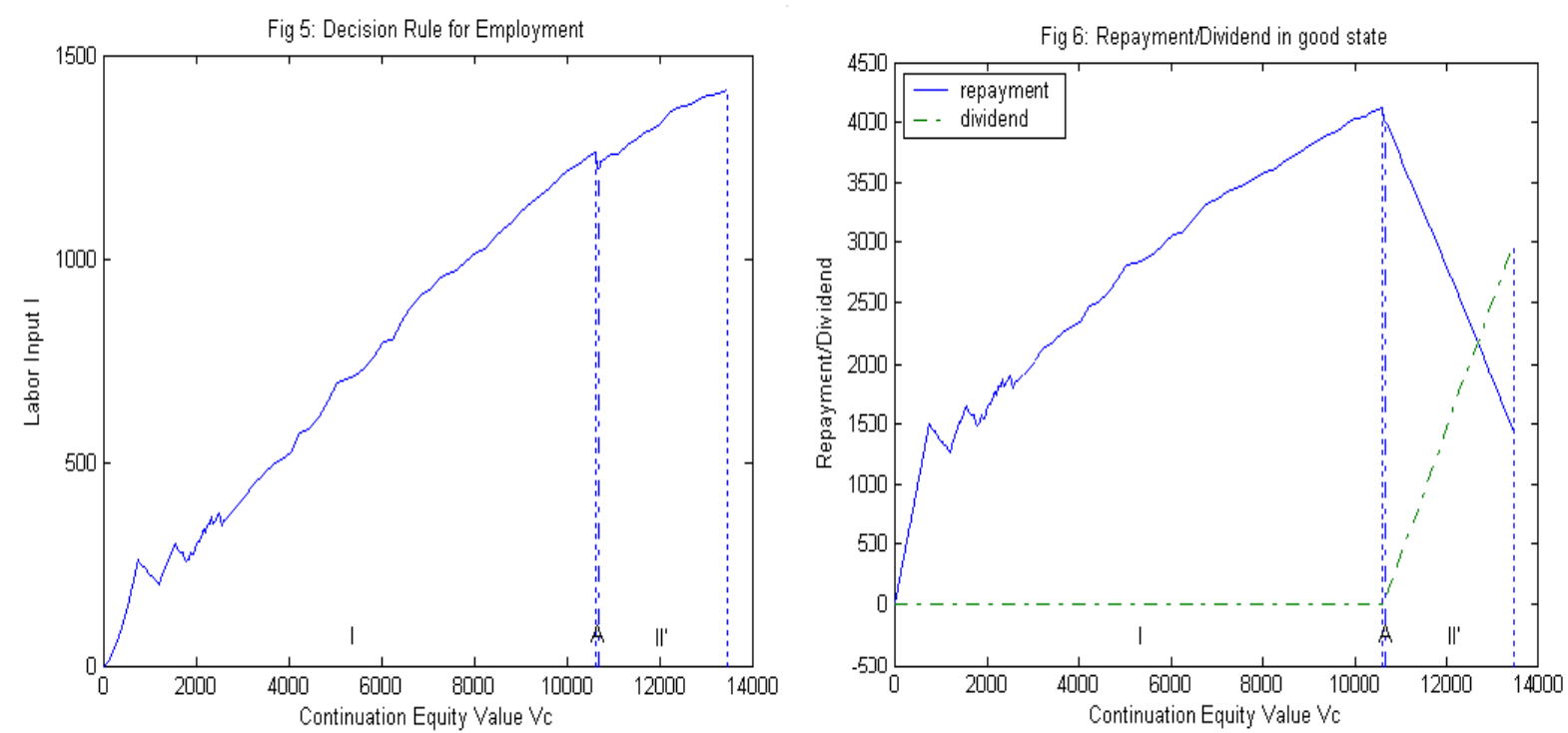

Notes: In both figures, region I denotes $\left[0, V_{1}\right]$, region A, $\left[V_{1}, \hat{V}\right]$, and region II', $[\hat{V}, \bar{V}]$. In the computation, the value functions $W$ and $\hat{W}$ are computed by following the procedure described in Appendix B. Once $W$ and $\hat{W}$ converge, the state space is discretized into even finer grids, especially for those regions where the labor input is not monotone. Then the labor input is re-computed for each grid point. This gives more accurate decision rule for labor input despite that it looks choppier. The value functions and decision rules for $V^{H}$ and $V^{L}$ are not sensitive to this refinement. 

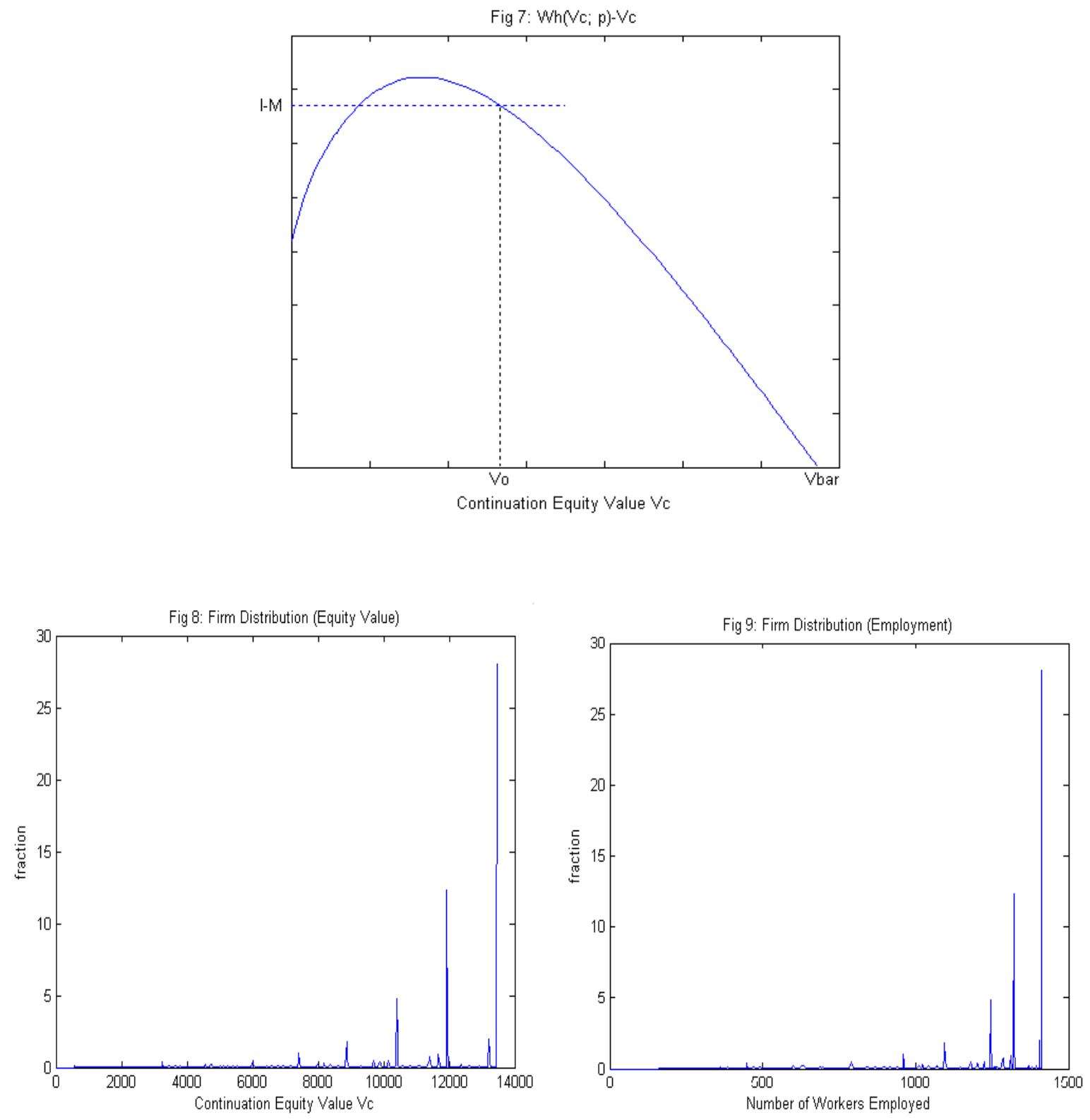
Table 2: Summary Statistics for Equilibria with and without frictions (baseline Calibration)

\begin{tabular}{|c|c|c|c|}
\hline & $\begin{array}{r}\text { Symmetric } \\
\text { Information }\end{array}$ & $\begin{array}{l}\text { Asymmetric } \\
\text { Information }\end{array}$ & $\operatorname{Data}(\mathrm{ASM})^{a}$ \\
\hline Avg. firm size & 1,137 & 1,157 & \\
\hline Std. of firm size & 0 & 322 & \\
\hline Maximum firm size & 1,137 & 1,413 & \\
\hline Minimum firm size & 1,137 & 153 & \\
\hline Entry/exit rate & 0 & $0.31 \%$ & \\
\hline Size of entrants & & 447 & \\
\hline Avg. size of exiters & & 206 & \\
\hline Emp. share of entrants & 0 & $0.12 \%$ & $1.41 \%$ \\
\hline Emp. share of exiters & 0 & $0.05 \%$ & $2.34 \%$ \\
\hline Job creation rate & 0 & $4.75 \%$ & $9.1 \%$ \\
\hline Job destruction rate & 0 & $4.75 \%$ & $10.3 \%$ \\
\hline Job creation share of entrants & 0 & $2.52 \%$ & $15.5 \%$ \\
\hline Job destruction share of exiters & 0 & $1.16 \%$ & $22.9 \%$ \\
\hline Output price & 0.905 & 1 & \\
\hline Total output $\left(\cdot 10^{7}\right)$ & 3.3961 & 3.0736 & \\
\hline Total employment $\left(\cdot 10^{7}\right)$ & 1.9671 & 1.8135 & \\
\hline Total \# of firms $\left(\cdot 10^{6}\right)$ & 1.7303 & 1.5669 & \\
\hline Total revenues $\left(\cdot 10^{7}\right)$ & 3.0736 & 3.0736 & \\
\hline Total payment to bank $\left(\cdot 10^{7}\right)$ & 2.7300 & 2.0811 & \\
\hline (fraction of total revenues) & $(88.8 \%)$ & $(67.7 \%)$ & \\
\hline $\begin{array}{l}\text { Total dividends of firms }\left(\cdot 10^{6}\right) \\
\text { (fraction of total revenues) }\end{array}$ & $\begin{array}{r}3.4365 \\
(11.2 \%)\end{array}$ & $\begin{array}{r}9.9257 \\
(32.3 \%)\end{array}$ & \\
\hline Total scrap value $\left(\cdot 10^{5}\right)$ & 0 & 2.1600 & \\
\hline bank short-term liability $\left(\cdot 10^{7}\right)$ & 11.736 & 3.9103 & \\
\hline
\end{tabular}

${ }^{a}$ : These statistics are from Davis, et al. (1996), which are based on plant-level data. 
Table 3: Exit Rates by Employer Size Category $(\%)^{b}$

\begin{tabular}{lrrrrr}
\hline & 1-year & 2-year & 5-year & 10-year & 15-year \\
\hline All & 0.3148 & 0.6271 & 1.5428 & 2.9224 & 4.2029 \\
\hline Classification I & & & & & \\
Small $(<500)$ & 4.0206 & 8.0334 & 18.9037 & 29.7434 & 36.0803 \\
Medium (500-999) & 0 & 0 & 0.4580 & 3.5562 & 6.7242 \\
Large (1000+) & 0 & 0 & 0 & 0.0743 & 0.4442 \\
\hline Classification II & & & & & \\
$<300$ & 11.8257 & 23.5589 & 38.7332 & 50.0709 & 56.3057 \\
$300-399$ & 0 & 0.1029 & 12.8942 & 25.4604 & 31.4855 \\
$400-499$ & 0 & 0 & 4.8047 & 13.8254 & 20.8168 \\
$500-599$ & 0 & 0 & 2.6545 & 8.7813 & 13.6167 \\
$600-699$ & 0 & 0 & 0.3244 & 5.6757 & 9.6386 \\
$700-799$ & 0 & 0 & 0 & 3.0407 & 6.9052 \\
$800-899$ & 0 & 0 & 0 & 1.8645 & 4.5861 \\
$900-999$ & 0 & 0 & 0 & 1.1881 & 2.9100 \\
$1000-1099$ & 0 & 0 & 0 & 0.4231 & 1.6608 \\
$1100-1199$ & 0 & 0 & 0 & 0.1668 & 0.9718 \\
$1200-1299$ & 0 & 0 & 0 & 0.0943 & 0.5382 \\
$1300+$ & 0 & 0 & 0 & 0.0061 & 0.1883 \\
\hline
\end{tabular}

${ }^{b}$ : This table gives the percentage of firms with base year employment in each category that exit in 1 year, 2 years, and etc. 
Table 4: Correlation of Job Flow Rates with Firm Size (average size)

\begin{tabular}{lrrr}
\hline & $\rho($ size, jcrate $)$ & $\rho($ size, jdrate $)$ & $\rho($ size, jrrate $)$ \\
\hline base-year size & -0.9325 & -0.7591 & -0.8408 \\
\hline current size & -0.6327 & -0.6080 & -0.6111 \\
\hline average size & -0.5073 & -0.5273 & -0.5105 \\
data (ASM) & -0.6260 & -0.5433 & -0.5882 \\
ratio & 0.81 & 0.97 & 0.87 \\
\hline
\end{tabular}


Table 5: Net and Gross Job Flow Rates by Employer Size Category (base-year size)

\begin{tabular}{lrrrrrrr}
\hline & $\begin{array}{r}\text { Job } \\
\text { creation }^{c}\end{array}$ & $\begin{array}{r}\text { Job des- } \\
\text { truction }\end{array}$ & $\begin{array}{r}\text { Job re- } \\
\text { allocation }\end{array}$ & $\begin{array}{r}\text { Net } \\
\text { growth }\end{array}$ & $\begin{array}{r}\text { Job } \\
\text { creation } \\
\text { share }\end{array}$ & $\begin{array}{r}\text { Job des- } \\
\text { truction } \\
\text { share }\end{array}$ & $\begin{array}{r}\text { Employ- } \\
\text { ment } \\
\text { share }\end{array}$ \\
\hline Classification I & & & & & & & \\
Small $(<500)$ & 18.0930 & 12.8874 & 30.9803 & 5.2056 & 11.4814 & 6.3856 & 2.3515 \\
Medium (500-999) & 14.0389 & 9.8457 & 23.8846 & 4.1931 & 31.3000 & 21.9518 & 10.5813 \\
Large (1000+) & 3.1189 & 3.9062 & 7.0251 & -0.7872 & 57.2185 & 71.6626 & 87.0672 \\
\hline Classification II & & & & & & & \\
$<300$ & 15.9229 & 17.3073 & 33.2302 & -1.3844 & 1.8396 & 1.9996 & 0.5483 \\
$300-399$ & 18.0653 & 11.8733 & 29.9387 & 6.1920 & 2.8989 & 1.9053 & 0.7616 \\
$400-499$ & 19.2498 & 11.3003 & 30.5501 & 7.9494 & 4.2103 & 2.4717 & 1.0380 \\
$500-599$ & 18.4555 & 10.9812 & 29.4367 & 7.4742 & 6.6809 & 2.4778 & 1.0708 \\
$600-699$ & 16.5949 & 11.7924 & 28.3872 & 4.8025 & 4.6034 & 3.2713 & 1.3165 \\
$700-799$ & 15.5283 & 10.2380 & 25.7662 & 5.2903 & 7.8125 & 5.1511 & 2.3878 \\
$800-899$ & 12.8517 & 8.8391 & 21.6908 & 4.0127 & 4.1094 & 2.8264 & 1.5176 \\
$900-999$ & 11.7485 & 9.1039 & 20.8524 & 2.6447 & 10.6328 & 8.2395 & 4.2953 \\
$1000-1099$ & 9.7433 & 6.1009 & 15.8441 & 3.6424 & 13.7877 & 8.6337 & 6.7161 \\
$1100-1199$ & 8.2420 & 6.4817 & 14.7237 & 1.7603 & 7.1393 & 5.6147 & 4.1111 \\
$1200-1299$ & 6.3879 & 5.2290 & 11.6169 & 1.1589 & 21.0220 & 17.2088 & 15.6188 \\
$1300+$ & 1.1950 & 3.1473 & 4.3424 & -1.9523 & 15.2633 & 40.2002 & 60.6180 \\
\hline
\end{tabular}

${ }^{c}$ : Since the base-year size for new entry firms is zero so that the job creation rates are not well defined, we exclude new entry firms when computing the job creation rate. 
Table 6: Net and Gross Job Flow Rates by Employer Size Category (current size)

\begin{tabular}{lrrrrrrr}
\hline & $\begin{array}{r}\text { Job } \\
\text { creation }\end{array}$ & $\begin{array}{r}\text { Job des- } \\
\text { truction }\end{array}$ & $\begin{array}{r}\text { Job re- } \\
\text { allocation }\end{array}$ & $\begin{array}{r}\text { Net } \\
\text { growth }\end{array}$ & $\begin{array}{r}\text { Job } \\
\text { creation } \\
\text { share }\end{array}$ & $\begin{array}{r}\text { Job des- } \\
\text { truction } \\
\text { share }\end{array}$ & $\begin{array}{r}\text { Employ- } \\
\text { ment } \\
\text { share }\end{array}$ \\
\hline Classification I & & & & & & & \\
Small (< 500) & 16.9158 & 16.9849 & 33.9007 & -0.0692 & 7.8028 & 7.8360 & 2.1892 \\
Medium (500-999) & 11.7427 & 11.5286 & 23.2712 & 0.2141 & 24.4259 & 23.9843 & 9.8720 \\
Large (1000+) & 3.6575 & 3.6789 & 7.3364 & -0.0215 & 67.7712 & 68.1797 & 87.9388 \\
\hline Classification II & & & & & & & \\
$<300$ & 31.8266 & 22.7705 & 54.5971 & 9.0560 & 3.2479 & 2.3243 & 0.4845 \\
$300-399$ & 12.2513 & 15.9398 & 28.1911 & -3.6885 & 1.6733 & 2.1775 & 0.6485 \\
$400-499$ & 12.9908 & 15.0068 & 27.9976 & -2.0160 & 2.9415 & 3.3987 & 1.0750 \\
$500-599$ & 14.5801 & 13.9481 & 28.5282 & 0.6320 & 3.6395 & 3.4823 & 1.1851 \\
$600-699$ & 13.9011 & 13.6902 & 27.5913 & 0.2109 & 4.1538 & 4.0912 & 1.4186 \\
$700-799$ & 10.7059 & 12.7641 & 23.4700 & -2.0582 & 3.6036 & 4.2972 & 1.5981 \\
$800-899$ & 10.4312 & 12.9131 & 23.3443 & -2.4820 & 6.4995 & 8.0472 & 2.9582 \\
$900-999$ & 11.4042 & 7.1310 & 18.5352 & 4.2733 & 6.5327 & 4.0849 & 2.7194 \\
$1000-1099$ & 8.6455 & 7.7884 & 16.4339 & 0.8572 & 9.6512 & 8.6963 & 5.3000 \\
$1100-1199$ & 7.0879 & 7.6302 & 14.7180 & -0.5423 & 15.4338 & 16.6186 & 10.3385 \\
$1200-1299$ & 2.8509 & 4.9846 & 7.8355 & -2.1337 & 7.9499 & 13.9034 & 13.2397 \\
$1300+$ & 2.7886 & 2.3220 & 5.1105 & 0.4666 & 34.6733 & 28.8784 & 59.0344 \\
\hline
\end{tabular}


Table 7: Net and Gross Job Flow Rates by Employer Size Category (average size)

\begin{tabular}{lrrrrrrr}
\hline & $\begin{array}{r}\text { Job } \\
\text { creation }\end{array}$ & $\begin{array}{r}\text { Job des- } \\
\text { truction }\end{array}$ & $\begin{array}{r}\text { Job re- } \\
\text { allocation }\end{array}$ & $\begin{array}{r}\text { Net } \\
\text { growth }\end{array}$ & $\begin{array}{r}\text { Job } \\
\text { creation } \\
\text { share }\end{array}$ & $\begin{array}{r}\text { Job des- } \\
\text { truction } \\
\text { share }\end{array}$ & $\begin{array}{r}\text { Employ- } \\
\text { ment } \\
\text { share }\end{array}$ \\
\hline Classification I & & & & & & & \\
Small $(<500)$ & 15.7944 & 18.3129 & 34.1072 & -2.5185 & 3.6013 & 4.3227 & 1.1082 \\
Medium (500-999) & 11.6887 & 11.5101 & 23.1988 & 0.1786 & 17.3340 & 17.0341 & 7.0671 \\
Large (1000+) & 4.0867 & 4.0640 & 8.1507 & 0.0228 & 79.0647 & 78.6431 & 91.8247 \\
\hline Classification II & & & & & & & \\
$<300$ & 9.2761 & 28.5274 & 37.8035 & -19.2513 & 0.1797 & 0.7035 & 0.1074 \\
$300-399$ & 15.4513 & 19.0430 & 34.4942 & -3.5917 & 1.3649 & 1.6888 & 0.4217 \\
$400-499$ & 16.6048 & 15.8706 & 32.4754 & 0.7342 & 2.0942 & 1.9807 & 0.5938 \\
$500-599$ & 15.0314 & 14.5872 & 29.6185 & 0.4442 & 2.3459 & 2.2628 & 0.7394 \\
$600-699$ & 13.8551 & 13.4696 & 27.3247 & 0.3854 & 2.7431 & 2.6545 & 0.9409 \\
$700-799$ & 12.5013 & 12.3327 & 24.8339 & 0.1686 & 3.2702 & 3.2199 & 1.2465 \\
$800-899$ & 11.1362 & 11.1217 & 22.2579 & 0.0145 & 3.9465 & 3.9420 & 1.6934 \\
$900-999$ & 9.8325 & 9.7207 & 19.5532 & 0.1118 & 5.1028 & 5.0387 & 2.4805 \\
$1000-1099$ & 8.2317 & 8.1842 & 16.4159 & 0.0475 & 7.5246 & 7.4809 & 4.3583 \\
$1100-1199$ & 6.5850 & 6.4982 & 13.0832 & 0.0868 & 12.9419 & 12.7748 & 9.3290 \\
$1200-1299$ & 4.8357 & 4.8042 & 9.6399 & 0.0315 & 24.4192 & 24.2704 & 23.9916 \\
$1300+$ & 2.9906 & 2.9824 & 5.9730 & 0.0082 & 34.0670 & 33.9830 & 54.0975 \\
\hline
\end{tabular}


Table 8: Net and Gross Job Flow Rates by Employer Size Category (average firm size): Mean Annual Rates, 1973-1988, ASM data

\begin{tabular}{lrrrrrrr}
\hline & $\begin{array}{r}\text { Job } \\
\text { creation }\end{array}$ & $\begin{array}{r}\text { Job des- } \\
\text { truction }\end{array}$ & $\begin{array}{r}\text { Job re- } \\
\text { allocation }\end{array}$ & $\begin{array}{r}\text { Net } \\
\text { growth }\end{array}$ & $\begin{array}{r}\text { Job } \\
\text { creation } \\
\text { share }\end{array}$ & $\begin{array}{r}\text { Job des- } \\
\text { truction } \\
\text { share }\end{array}$ & $\begin{array}{r}\text { Employ- } \\
\text { ment } \\
\text { share }\end{array}$ \\
\hline $\begin{array}{l}\text { Small } \\
(<500)\end{array}$ & 11.94 & 12.86 & 24.8 & -0.92 & 40.6 & 38.8 & 30.9 \\
$\begin{array}{l}\text { Medium } \\
(500-4999)\end{array}$ & 9.0 & 9.8 & 18.8 & -0.8 & 19.9 & 19.2 & 19.5 \\
$\begin{array}{l}\text { Large } \\
(5000+)\end{array}$ & 7.0 & 8.45 & 15.45 & -1.45 & 39.7 & 42.1 & 49.6 \\
\hline
\end{tabular}


Table 9: Exit Rates by Employer Age Category (\%)

\begin{tabular}{llllr}
\hline Age categories & 1-year & 2-year & 5-year & 10-year \\
\hline$\leq 5$ years old & 1.0438 & 2.9549 & 8.9274 & 15.4221 \\
6-10 years old & 1.9889 & 3.4123 & 7.2847 & 12.8015 \\
11-15 years old & 1.4500 & 2.4761 & 5.8652 & 9.7864 \\
15 years more & 0.2251 & 0.4493 & 1.1034 & 2.1535 \\
\hline
\end{tabular}

Table 10: Net and Gross Job Flow Rates by Employer Age Category

\begin{tabular}{lrrrrrrr}
\hline & $\begin{array}{r}\text { Job } \\
\text { creation }\end{array}$ & $\begin{array}{r}\text { Job des- } \\
\text { truction }\end{array}$ & $\begin{array}{r}\text { Job re- } \\
\text { allocation }\end{array}$ & $\begin{array}{r}\text { Net } \\
\text { growth }\end{array}$ & $\begin{array}{r}\text { Job } \\
\text { creation } \\
\text { share }\end{array}$ & $\begin{array}{r}\text { Job des- } \\
\text { truction } \\
\text { share }\end{array}$ & $\begin{array}{r}\text { Employ- } \\
\text { ment } \\
\text { share }\end{array}$ \\
\hline$\leq 5$ years old & 0.4925 & 0.2318 & 0.7243 & 0.2608 & 0.0476 & 0.0145 & 0.0076 \\
6-10 years old & 0.1778 & 0.1985 & 0.3763 & -0.0207 & 0.0199 & 0.0154 & 0.0090 \\
$11-15$ years old & 0.1352 & 0.1471 & 0.2824 & -0.0119 & 0.0162 & 0.0131 & 0.0099 \\
15 years more & 0.0838 & 0.0996 & 0.1833 & -0.0158 & 0.9163 & 0.9570 & 0.9753 \\
\hline
\end{tabular}


Table 11: Comparative Static Properties

\begin{tabular}{|c|c|c|c|}
\hline \multicolumn{4}{|l|}{ 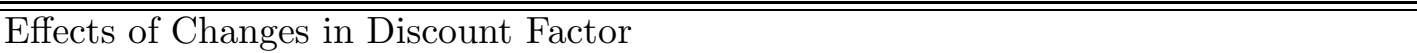 } \\
\hline & $\beta=\frac{1}{106}$ & $\begin{array}{r}\text { baseline } \\
\left(\beta=\frac{1}{1065}\right)\end{array}$ & $\beta=\frac{1}{1.07}$ \\
\hline Entry/exit rate(\%) & 0.24 & 0.31 & 0.39 \\
\hline Relative size of entrants & 0.54 & 0.54 & 0.55 \\
\hline Relative size of exiters & 0.33 & 0.33 & 0.33 \\
\hline Job Creation/destruction rate (\%) & 3.99 & 4.75 & 5.26 \\
\hline Increase in output price $(\%)$ & 9.67 & 10.5 & 11.41 \\
\hline Output $\operatorname{loss}(\%)$ & 8.81 & 9.5 & 10.24 \\
\hline Employment loss $(\%)$ & 6.79 & 7.81 & 8.82 \\
\hline \multicolumn{4}{|l|}{ Effects of Changes in Project Riskiness } \\
\hline & $\pi=0.50$ & $\begin{array}{r}\text { baseline } \\
(\pi=0.51)\end{array}$ & $\pi=0.55$ \\
\hline Entry/exit rate(\%) & 0.33 & 0.31 & 0.23 \\
\hline Relative size of entrants & 0.54 & 0.54 & 0.54 \\
\hline Relative size of exiters & 0.33 & 0.33 & 0.34 \\
\hline Job Creation/destruction rate (\%) & 4.98 & 4.75 & 3.83 \\
\hline Increase in output price $(\%)$ & 10.96 & 10.5 & 9.02 \\
\hline Output $\operatorname{loss}(\%)$ & 9.88 & 9.50 & 8.27 \\
\hline Employment loss (\%) & 8.28 & 7.81 & 5.98 \\
\hline \multicolumn{4}{|l|}{ Effects of Changes in Entry Cost } \\
\hline & & baseline & \\
\hline & $I=10,000$ & $(I=10,478)$ & $I=11,000$ \\
\hline Entry/exit rate(\%) & 0.345 & 0.31 & 0.36 \\
\hline Relative size of entrants & 0.63 & 0.54 & 0.48 \\
\hline Relative size of exiters & 0.395 & 0.33 & 0.29 \\
\hline Job Creation/destruction rate (\%) & 4.51 & 4.75 & 5.37 \\
\hline Increase in output price(\%) & 8.26 & 10.5 & 16.76 \\
\hline Output $\operatorname{loss}(\%)$ & 7.63 & 9.50 & 14.35 \\
\hline Employment loss (\%) & 7.49 & 7.81 & 9.08 \\
\hline \multicolumn{4}{|c|}{ Effects of Changes in Firms' Initial Wealth } \\
\hline & $M=2500$ & $\begin{array}{r}\text { baseline } \\
(M=3,254)\end{array}$ & $M=4,000$ \\
\hline Entry/exit rate(\%) & 0.33 & 0.31 & 0.29 \\
\hline Relative size of entrants & 0.42 & 0.54 & 0.67 \\
\hline Relative size of exiters & 0.285 & 0.33 & 0.367 \\
\hline Job Creation/destruction rate (\%) & 4.78 & 4.75 & 4.56 \\
\hline Increase in output price $(\%)$ & 17.39 & 10.5 & 6.86 \\
\hline Output $\operatorname{loss}(\%)$ & 14.81 & 9.50 & 6.42 \\
\hline Employment loss (\%) & 8.23 & 7.81 & 7.55 \\
\hline
\end{tabular}




\section{APPENDIX B: Analytical Proofs}

PROOF of LEMMA 1: Consider a sequence of candidates for $\bar{V},\left\{\bar{V}_{0}, \bar{V}_{1}, \bar{V}_{2} \ldots\right\}$. Let $\bar{V}_{0}=\tilde{V}(p)$. Then $W_{\left[0, \bar{V}_{0}\right]}\left(\bar{V}_{0} ; p\right)=\tilde{W}(p)$, so $B_{\left[0, \bar{V}_{0}\right]}\left(\bar{V}_{0} ; p\right)<0$. Recall that $B_{\left[0, \bar{V}_{0]}\right]}(0 ; p)=W_{\left[0, \bar{V}_{0}\right]}(0 ; p)-0=S>$ 0 . By continuity of $B_{\left[0, \bar{V}_{0}\right]}$, there exists the highest point $\bar{V}_{1} \in\left(0, \bar{V}_{0}\right)$ such that $B_{\left[0, \bar{V}_{0}\right]}\left(\bar{V}_{1} ; p\right)=0$. Since $\bar{V}_{1}<\bar{V}_{0}, W_{\left[0, \bar{V}_{1}\right]}\left(\bar{V}_{1} ; p\right) \leq W_{\left[0, \bar{V}_{0}\right]}\left(\bar{V}_{1} ; p\right)$. So $B_{\left[0, \bar{V}_{1}\right]}\left(\bar{V}_{1} ; p\right) \leq B_{\left[0, \bar{V}_{0}\right]}\left(\bar{V}_{1} ; p\right)=0$. Again denote $\bar{V}_{2}$ the highest point in $\left(0, \bar{V}_{1}\right]$ such that $B_{\left[0, \bar{V}_{1}\right]}\left(\bar{V}_{2} ; p\right)=0$. Continuing this process defines a nonincreasing sequence $\left\{\bar{V}_{0}, \bar{V}_{1}, \bar{V}_{2} \ldots\right\}$, with $0<\bar{V}_{i} \leq \tilde{V}, B_{\left[0, \bar{V}_{i}\right]}\left(\bar{V}_{i+1}\right)=0$. It converges to a unique limit, call it $\bar{V}$. Berge's Theorem of the Maximum guarantees that the value function $W$ and hence $B$ moves continuously with its constraint set parameter. So $B_{[0, \bar{V}]}(\bar{V} ; p)=0$. By construction, for any $V>\bar{V}, B_{[0, V]}(V ; p)<0$. So any $V>\bar{V}$ cannot be feasibly promised. Finally, since $W_{[0, \bar{V}]}(V ; p)$ is concave and increasing in $V$, and $W_{[0, \bar{V}]}(0 ; p)=S>0$, we have $W_{[0, \bar{V}]}(V ; p)>V$ for all $V<\bar{V}$, i.e. $B_{[0, \bar{V}]}(V ; p)>0$ for $V<\bar{V}$. In other words, any $V<\bar{V}$ can be feasibly promised. So $\bar{V}$ is the upper bound on feasible value entitlements.

PROOF OF LEMMA 2: First note that for $V=0^{17}, V^{H}(V)=0<\bar{V}$. For $V=\bar{V}$, we can show that $V^{H}(V)=\bar{V}$ by contradiction. Consider $\left(P_{2}\right)$ with $V=\bar{V}$. Suppose its solution is $\left(l, \tau, V^{H}, V^{L}\right)$ with $V^{H}<\bar{V}$. If $\tau=p f(l)$, then $\bar{V}=\beta\left(\pi V^{H}+(1-\pi) V^{L}\right)<\beta \bar{V}$. If $\tau<p f(l)$, increasing $\tau$ and $V^{H}$ can make the objective strictly higher. So $V^{H}(\bar{V})=\bar{V}$. By continuity of the policy function $V^{H}(V)$, there exists $0<V_{1} \leq \bar{V}$ such that $V^{H}\left(V_{1}\right)=\bar{V}, V^{H}(V)<\bar{V}$ for $V<V_{1}$. By $(10), V^{L}(V) \leq V^{H}(V)$ for all $V \in[0, \bar{V}]$. So $V^{L}(V)<\bar{V}$ for $V<V_{1}$.

\section{PROOF OF PROPOSITION 3:}

(i) If $V=0$, this is obvious, since $l(0)=0, \tau(0)=0$. Consider an arbitrary $0<V<V_{1}$, suppose the solution to $\left(P_{2}\right)$ is $\left(l, \tau, V^{H}, V^{L}\right)$. From Lemma 2, we know $V^{H}<\bar{V}$. If $\tau<p f(l)$, since $W$ is strictly increasing, the objective of $\left(P_{2}\right)$ can be strictly increased by increasing $\tau$ and $V^{H}$ in a way that keeps all constraints hold. So $\tau(V)=p f(l(V))$ for any $V<V_{1}$. By continuity of $\tau(V)$ and $l(V)$, the equality also holds for $V=V_{1}$. So (11) is binding for $V \in\left[0, V_{1}\right]$.

(ii) This is obviously true for $V=0$. Suppose there exists $V_{0} \in\left(0, V_{1}\right]$ such that $\tau\left(V_{0}\right)<$ $\beta\left(V^{H}\left(V_{0}\right)-V^{L}\left(V_{0}\right)\right)$. Since $\tau\left(V_{0}\right)=p f\left(l\left(V_{0}\right)\right)>0, V^{H}\left(V_{0}\right)>V^{L}\left(V_{0}\right)$. Now consider two cases.

Case 1. $V^{H}\left(V_{0}\right)>V_{r}$. Since $\tau\left(V_{0}\right)<\beta\left[V^{H}\left(V_{0}\right)-V^{L}\left(V_{0}\right)\right]$, there exists $\xi>0$, such that $\tau\left(V_{0}\right) \leq \beta\left[\left(V^{H}\left(V_{0}\right)-(1-\pi) \xi\right)-\left(V^{L}\left(V_{0}\right)+\pi \xi\right)\right]$. Consider a choice vector $\left(l\left(V_{0}\right), \tau\left(V_{0}\right), V^{H}\left(V_{0}\right)-\right.$ $\left.(1-\pi) \xi, V^{L}\left(V_{0}\right)+\pi \xi\right)$. It's easy to see that it satisfies all the constraints of $\left(P_{2}\right)$. Since $W(V)$ is strictly increasing, linear for $V \in\left[0, V_{r}\right]$ and strictly concave for $V>V_{r}$, by Jensen's inequality,

$$
\pi W\left(V^{H}\left(V_{0}\right)-(1-\pi) \xi\right)+(1-\pi) W\left(V^{L}\left(V_{0}\right)+\pi \xi\right)>\pi W\left(V^{H}\left(V_{0}\right)\right)+(1-\pi) W\left(V^{L}\left(V_{0}\right)\right) .
$$

This contradicts that $\left(l\left(V_{0}\right), \tau\left(V_{0}\right), V^{H}\left(V_{0}\right), V^{L}\left(V_{0}\right)\right)$ is the optimal solution.

Case 2. $V^{H}\left(V_{0}\right) \leq V_{r}$. We first show that $l\left(V_{0}\right)<l^{\star}(p)$. By (i), $\tau\left(V_{0}\right)=p f\left(l\left(V_{0}\right)\right)$, so $\pi V^{H}\left(V_{0}\right)+(1-\pi) V^{L}\left(V_{0}\right)=\frac{V_{0}}{\beta}$. Since $V^{L}\left(V_{0}\right)<V^{H}\left(V_{0}\right) \leq V_{r}, \frac{V_{0}}{\beta}<V_{r}$ and hence $V_{0}<V_{r}$. Since $W(V)$ is linear for $V \leq V_{r}, \pi W\left(V^{H}\left(V_{0}\right)\right)+(1-\pi) W\left(V^{L}\left(V_{0}\right)\right)=W\left(\frac{V_{0}}{\beta}\right)$. So $\hat{W}\left(V_{0}\right)=$ $\pi p f\left(l\left(V_{0}\right)\right)-l\left(V_{0}\right)+\beta\left[\pi W\left(V^{H}\left(V_{0}\right)\right)+(1-\pi) W\left(V^{L}\left(V_{0}\right)\right]=\pi p f\left(l\left(V_{0}\right)\right)-l\left(V_{0}\right)+\beta W\left(\frac{V_{0}}{\beta}\right)\right.$. Since $V_{0}<V_{r}, \hat{W}\left(V_{0}\right)<W\left(V_{0}\right)$. By Proposition 1, for $V \leq V_{r}, W(V)=S+\frac{W\left(V_{r}\right)-S}{V_{r}} V$. So $\pi p f\left(l\left(V_{0}\right)\right)-$ $l\left(V_{0}\right)+\beta\left[S+\frac{W\left(V_{r}\right)-S}{V_{r}} \frac{V_{0}}{\beta}\right]<S+\frac{W\left(V_{r}\right)-S}{V_{r}} V_{0}$, which implies $S>\frac{\pi p f\left(l\left(V_{0}\right)\right)-l\left(V_{0}\right)}{1-\beta}$. Since $S<I-M<$

\footnotetext{
${ }^{17}$ For simplicity, throughout the proofs, we use $V$ to denote either the value entitlement to an entrepreneur at the beginning of a period or the continuation value entitlement $\left(V_{c}\right)$.
} 
$I=\frac{\pi p f\left(l^{\star}(p)\right)-l^{\star}(p)}{1-\beta}, l\left(V_{0}\right)<l^{\star}(p)$. With this result and $\tau\left(V_{0}\right)<\beta\left[V^{H}\left(V_{0}\right)-V^{L}\left(V_{0}\right)\right]$, we can find $\xi, \xi^{\prime}>0$, such that $\tau+\xi \leq \beta\left[V^{H}\left(V_{0}\right)-V^{L}\left(V_{0}\right)\right], \tau+\xi=p f\left(l\left(V_{0}\right)+\xi^{\prime}\right)$, and $l\left(V_{0}\right)+\xi^{\prime} \leq l^{\star}(p)$. It's easy to see that the choice vector $\left(l\left(V_{0}\right)+\xi^{\prime}, \tau\left(V_{0}\right)+\xi, V^{H}\left(V_{0}\right), V^{L}\left(V_{0}\right)\right)$ also satisfies (9). But it yields a higher value for the objective of $\left(P_{2}\right)$, because $\pi p f(l)-l$ is strictly increasing for $l<l^{\star}(p)$. This is a contradiction.

In both cases, we get contradictions. So the incentive compatibility constraint is binding for $V \in\left[0, V_{1}\right]$.

(iii) First $l(0)=0<l^{\star}(p)$. For any $V \in\left(0, V_{1}\right]$, also consider the two cases: $V^{H}(V)>V_{r}$ and $V^{H}(V) \leq V_{r}$. For the second case, $l(V)<l^{\star}(p)$ is already proved in (ii). Now consider the first case. Since both (10) and (11) are binding, $V^{H}$ and $V^{L}$ can be solved in terms of $V$ and $l$, $V^{H}=\frac{V+(1-\pi) p f(l)}{\beta}, V^{L}=\frac{V-\pi p f(l)}{\beta}$. Then $\left(P_{2}\right)$ can be reduced to

$$
\left(P_{2}^{\prime}\right)\left\{\begin{array}{cl}
\hat{W}(V) & =\max _{l \geq 0}\left\{\pi p f(l)-l+\beta\left\{\pi W\left(V^{H}\right)+(1-\pi) W\left(V^{L}\right)\right\}\right\} \\
\text { s.t. } & V^{H}=\frac{V+(1-\pi) p f(l)}{\beta} \\
& V^{L}=\frac{V-\pi p f(l)}{\beta} \geq 0
\end{array}\right.
$$

Since $V>0, l(V)>0$ and it satisfies the first order condition

$$
\pi p f^{\prime}(l(V)) \geq \frac{1}{1-(1-\pi)\left[W^{\prime}\left(V^{L}(V)\right)-W^{\prime}\left(V^{H}(V)\right)\right]} \text {, with equality if } \quad V^{L}(V)>0 .
$$

Note that by (i) and (ii), $\beta\left[V^{H}(V)-V^{L}(V)\right]=\tau(V)=p f(l(V))>0$, so $V^{L}(V)<V^{H}(V)$. Since $W$ is linear for $V \leq V_{r}$ and strictly concave for $V>V_{r}, W^{\prime}\left(V^{L}\right)>W^{\prime}\left(V^{H}\right)$. So $\pi p f^{\prime}(l(V))>1$, while $\pi p f^{\prime}\left(l^{\star}(p)\right)=1$. By strict concavity of $f, l(V)<l^{\star}(p)$.

(iv). First, since $l(V)>0$ for $V>0, V^{H}(V)=\frac{V+(1-\pi) p f(l(V))}{\beta}>V$. Now consider problem $\left(P_{2}\right)$ with $V \in\left(0, V_{1}\right]$. Since both $(10)$ and $(11)$ are binding, $\left(P_{2}\right)$ can be rewritten as

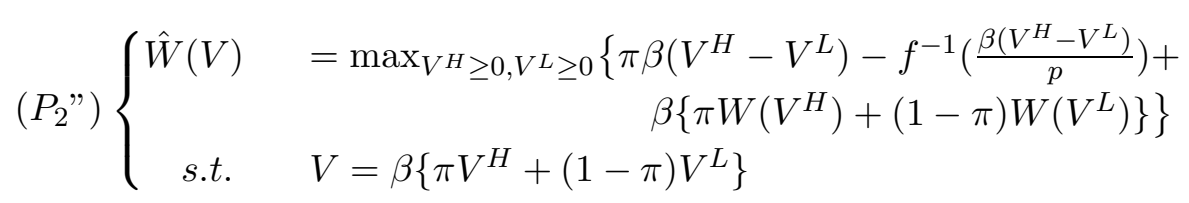

Since $V^{H}(V)>0, V^{L}(V) \geq 0, V^{H}(V)$ and $V^{L}(V)$ satisfies the first order conditions

$$
\begin{aligned}
& W^{\prime}\left(V^{H}\right)=\lambda-\left[1-\frac{f^{-1^{\prime}}\left(\frac{\beta\left(V^{H}-V^{L}\right)}{p}\right)}{\pi p}\right] \\
& W^{\prime}\left(V^{L}\right) \leq \lambda+\frac{\pi}{1-\pi}\left[1-\frac{f^{-1^{\prime}}\left(\frac{\beta\left(V^{H}-V^{L}\right)}{p}\right)}{\pi p}\right] \text {, with equality if } V^{L}>0,
\end{aligned}
$$

where $\lambda>0$ is the Lagrangian multiplier on the constraint. If $V^{L}(V)=0$, then $V^{L}(V)<V$. If $V^{L}(V)>0$, then we have equality in the first order condition with respect to $V^{L}$. Since $l(V) \equiv$ $f^{-1}\left(\frac{\beta\left(V^{H}-V^{L}\right)}{p}\right)<l^{\star}(p)$, and $f^{-1}$ is convex, $f^{-1^{\prime}}\left(\frac{\beta\left(V^{H}-V^{L}\right)}{p}\right)<f^{-1^{\prime}}\left(f\left(l^{\star}(p)\right)\right)=\frac{1}{f^{\prime}\left(l^{\star}(p)\right)}=\pi p$. So $W^{\prime}\left(V^{L}(V)\right)>\lambda$. By the Envelope theorem, $\lambda=\hat{W}^{\prime}(V) \geq W^{\prime}(V)$. So $W^{\prime}\left(V^{L}(V)\right)>W^{\prime}(V)$, and by concavity of $W, V^{L}(V)<V$. This proves $V^{L}(V)<V<V^{H}(V)$ for $0<V \leq V_{1}$.

Now suppose there exist $V, V^{\prime} \in\left[0, V_{1}\right], V<V^{\prime}$, such that $V^{H}(V) \geq V^{H}\left(V^{\prime}\right)$. Then $V^{L}\left(V^{\prime}\right)>$ $V^{L}(V)$ by the constraint of $\left(P_{2}\right.$ "). So $\beta\left(V^{H}\left(V^{\prime}\right)-V^{L}\left(V^{\prime}\right)\right)<\beta\left(V^{H}(V)-V^{L}(V)\right)$. Since $f^{-1}$ is 
strictly convex,

$$
f^{-1^{\prime}}\left[\frac{\beta\left(V^{H}\left(V^{\prime}\right)-V^{L}\left(V^{\prime}\right)\right)}{p}\right]<f^{-1^{\prime}}\left[\frac{\beta\left(V^{H}(V)-V^{L}(V)\right)}{p}\right] .
$$

So

$$
\begin{aligned}
& \hat{W}^{\prime}\left(V^{\prime}\right)=\lambda\left(V^{\prime}\right)=W^{\prime}\left(V^{H}\left(V^{\prime}\right)\right)+\left[1-\frac{f^{-1^{\prime}\left(\frac{\beta\left(V^{H}\left(V^{\prime}\right)-V^{L}\left(V^{\prime}\right)\right)}{p}\right)}}{\pi p}\right]
\end{aligned}
$$

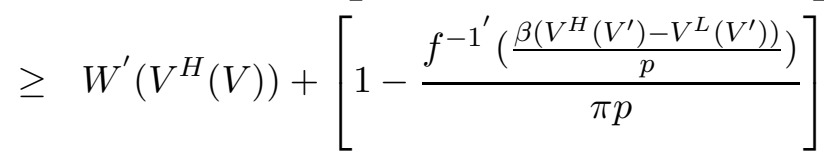

$$
\begin{aligned}
& >W^{\prime}\left(V^{H}(V)\right)+\left[1-\frac{f^{-1^{\prime}\left(\frac{\beta\left(V^{H}(V)-V^{L}(V)\right)}{p}\right)}}{\pi p}\right] \\
& =\lambda(V)=\hat{W}^{\prime}(V),
\end{aligned}
$$

i.e. $\hat{W}^{\prime}\left(V^{\prime}\right)>\hat{W}^{\prime}(V)$, which is a contradiction to the fact that $\hat{W}$ is concave. So for any $V, V^{\prime} \in$ $\left[0, V_{1}\right], V<V^{\prime}, V^{H}(V)<V^{H}\left(V^{\prime}\right)$, i.e. $V^{H}(V)$ is strictly increasing on $\left[0, V_{1}\right]$.

To prove that $V^{L}(V)$ is non-decreasing on $\left[0, V_{1}\right]$, consider $V, V^{\prime} \in\left[0, V_{1}\right], V<V^{\prime}$. If $V^{L}(V)=0$, then since $V^{L}\left(V^{\prime}\right) \geq 0$, it's obviously true that $V^{L}\left(V^{\prime}\right) \geq V^{L}(V)$. If $V^{L}(V)>0, V^{L}\left(V^{\prime}\right) \geq V^{L}(V)$ can be proved by contradiction. If $V^{L}\left(V^{\prime}\right)<V^{L}(V)$, then $V^{H}\left(V^{\prime}\right)>V^{H}(V)$. So

$$
\begin{aligned}
& \hat{W}^{\prime}\left(V^{\prime}\right)=\lambda\left(V^{\prime}\right) \geq W^{\prime}\left(V^{L}\left(V^{\prime}\right)\right)-\frac{\pi}{1-\pi}\left[1-\frac{f^{-1^{\prime}\left(\frac{\beta\left(V^{H}\left(V^{\prime}\right)-V^{L}\left(V^{\prime}\right)\right)}{p}\right)}}{\pi p}\right] \\
& \geq W^{\prime}\left(V^{L}(V)\right)-\frac{\pi}{1-\pi}\left[1-\frac{f^{-1^{\prime}}\left(\frac{\beta\left(V^{H}\left(V^{\prime}\right)-V^{L}\left(V^{\prime}\right)\right)}{p}\right)}{\pi p}\right] \\
& >W^{\prime}\left(V^{L}(V)\right)-\frac{\pi}{1-\pi}\left[1-\frac{f^{-1^{\prime}\left(\frac{\beta\left(V^{H}(V)-V^{L}(V)\right)}{p}\right)}}{\pi p}\right] \\
& =\lambda(V)=\hat{W}^{\prime}(V),
\end{aligned}
$$

Again, we get a contradiction to $\hat{W}$ being concave. Therefore $V^{L}(V)$ is non-decreasing on $\left[0, V_{1}\right]$.

PROOF OF LEMMA 3:

First, by (iv) of Proposition $3, V^{L}\left(V_{1}\right)<V^{H}\left(V_{1}\right)=\bar{V}$. So

$$
V_{1}=\beta\left(\pi \bar{V}+(1-\pi) V^{L}\left(V_{1}\right)\right)<\beta \bar{V}<\bar{V} .
$$

Suppose $V_{1} \leq V_{r}$, consider problem $\left(P_{2}^{\prime}\right)$ with $V=V_{1}$. By the Envelope theorem, $\hat{W}^{\prime}\left(V_{1}\right)=$ $\pi W^{\prime}\left(V^{H}\left(V_{1}\right)\right)+(1-\pi) W^{\prime}\left(V^{L}\left(V_{1}\right)\right)=\pi W^{\prime}(\bar{V})+(1-\pi) W^{\prime}\left(V^{L}\left(V_{1}\right)\right)$. Recall that $W$ is linear on $\left[0, V_{r}\right]$, and strictly concave on $\left[V_{1}, \bar{V}\right]$. Since $V^{L}\left(V_{1}\right)<V_{1} \leq V_{r}, W^{\prime}\left(V^{L}\left(V_{1}\right)\right)=W^{\prime}\left(V_{1}\right)$. Since $\bar{V}>V_{1}$ and $\bar{V}>V_{r}, W^{\prime}(\bar{V})<W^{\prime}\left(V_{1}\right)$. So $\hat{W}^{\prime}\left(V_{1}\right)<W^{\prime}\left(V_{1}\right)$. However, $V_{1} \leq V_{r}$ implies that $\hat{W}^{\prime}\left(V_{1}\right) \geq W^{\prime}\left(V_{1}\right)$. So $V_{1}>V_{r}$.

\section{PROOF OF PROPOSITION 4:}


(i) By construction, $V^{H}\left(V_{1}\right)=\bar{V}$, and it has been proved that $V^{H}(\bar{V})=\bar{V}$ in the proof of Lemma 2. Now suppose there exists $V_{0} \in\left(V_{1}, \bar{V}\right)$, such that $V^{H}\left(V_{0}\right)<\bar{V}$. If $\tau\left(V_{0}\right)<p f\left(l\left(V_{0}\right)\right)$, the objective of $\left(P_{2}\right)$ can be strictly increased by increasing $\tau\left(V_{0}\right)$ and $V^{H}\left(V_{0}\right)$ in a way that keeps all constraints hold. If $\tau\left(V_{0}\right)=p f\left(l\left(V_{0}\right)\right)$ and $\tau\left(V_{0}\right)<\beta\left(V^{H}\left(V_{0}\right)-V^{L}\left(V_{0}\right)\right)$, then $V_{0}=$ $\beta\left(\pi V^{H}\left(V_{0}\right)+(1-\pi) V^{L}\left(V_{0}\right)\right), V^{H}\left(V_{0}\right)>V^{L}\left(V_{0}\right)$. Since $V_{0}>V_{1}>V_{r}, V^{H}\left(V_{0}\right)>V_{r}$. Then as proved before the objective of $\left(P_{2}\right)$ can be strictly increased by lowering $V^{H}\left(V_{0}\right)$ and increasing $V^{L}\left(V_{0}\right)$. If $\tau\left(V_{0}\right)=p f\left(l\left(V_{0}\right)\right)$ and $\tau\left(V_{0}\right)=\beta\left(V^{H}\left(V_{0}\right)-V^{L}\left(V_{0}\right)\right)$, by the argument of part (iv) of Proposition $3, V^{H}\left(V_{0}\right)>V^{H}\left(V_{1}\right)=\bar{V}$. So $V^{H}(V)=\bar{V}$ for all $V \in\left[V_{1}, \bar{V}\right]$.

(ii) It holds for $V=V_{1}$. Suppose there exists $V_{0} \in\left(V_{1}, \bar{V}\right]$, such that $\tau\left(V_{0}\right)<\beta\left(V^{H}\left(V_{0}\right)-\right.$ $V^{L}\left(V_{0}\right)$ ), where $V^{H}\left(V_{0}\right)=\bar{V}>V_{r}$. Again, by concavity of $W$, the objective of $\left(P_{2}\right)$ can be made strictly higher by lowering $V^{H}\left(V_{0}\right)$ and increasing $V^{L}\left(V_{0}\right)$ in a way that makes all constraints hold. So (10) is binding on $\left[V_{1}, \bar{V}\right]$.

(iii) Consider any $V \in\left[V_{1}, \bar{V}\right]$, the problem of $\left(P_{1}\right)$ and $\left(P_{2}\right)$ can be reduced to

$$
\left(P^{\prime}\right)\left\{\begin{array}{cl}
W(V) & =\max _{l \geq 0}\left\{\pi p f(l)-l+\beta\left\{\pi W(\bar{V})+(1-\pi) W\left(V^{L}\right)\right\}\right\} \\
\text { s.t. } & V^{L}=\frac{V-\pi p f(l)}{\beta} \geq 0 \\
& (1-\pi) p f(l) \geq \beta \bar{V}-V
\end{array}\right.
$$

where the second constraint is the limited liability constraint. Note that the first constraint implies $p f(l) \leq \frac{V}{\pi}$. And the second constraint implies $p f(l) \geq \frac{\beta \bar{V}-V}{1-\pi}$. So a necessary condition for $\left(P^{\prime}\right)$ to be meaningful is $\frac{V}{\pi} \geq \frac{\beta \bar{V}-V}{1-\pi}$ or equivalently, $V \geq \beta \pi \bar{V}$. Note that this is true for $V_{1}$, since $V_{1}=\beta\left(\pi \bar{V}+(1-\pi) V^{L}\left(V_{1}\right)\right) \geq \beta \pi \bar{V}$. So this condition holds for any $V \in\left[V_{1}, \bar{V}\right]$.

Consider two possible cases. First, $(1-\pi) p f(l(V))=\beta \bar{V}-V$. Since $\bar{V}=V^{H}\left(V_{1}\right)=$ $\frac{V_{1}+(1-\pi) p f\left(l\left(V_{1}\right)\right)}{\beta}$, then $(1-\pi) p f(l(V))=\beta \frac{V_{1}+(1-\pi) p f\left(l\left(V_{1}\right)\right)}{\beta}-V \leq V_{1}+(1-\pi) p f\left(l\left(V_{1}\right)\right)-V_{1}=$ $(1-\pi) p f\left(l\left(V_{1}\right)\right)<(1-\pi) p f\left(l^{\star}(p)\right)$. So $l(V)<l^{\star}(p)$. Second, $(1-\pi) p f(l(V))>\beta \bar{V}-V$. Then $l(V)$ satisfies the first order condition

$$
\pi p f^{\prime}(l(V)) \geq \frac{1}{1-(1-\pi) W^{\prime}\left(V^{L}(V)\right)}, \text { with equality if } \quad V^{L}(V)>0 .
$$

Clearly $\pi p f^{\prime}(l(V))>1$, so $l(V)<l^{\star}(p)$.

(iv) Consider the problem $\left(P^{\prime}\right)$ for any $V \in\left[V_{1}, \bar{V}\right]$. Since (10) is binding, $l$ can be solved in terms of $V^{L}, l=f^{-1}\left(\frac{V-\beta V^{L}}{\pi p}\right)$. And (11) can be rewritten as $\beta(1-\pi) V^{L} \leq V-\pi \beta \bar{V}$. So the problem can be rewritten as

$$
\left(P^{\prime \prime}\right)\left\{\begin{array}{cl}
W(V) & =\max _{V^{L} \in[0, \bar{V}]}\left\{V-\beta V^{L}-f^{-1}\left(\frac{V-\beta V^{L}}{\pi p}\right)+\beta\left\{\pi W(\bar{V})+(1-\pi) W\left(V^{L}\right)\right\}\right\} \\
\text { s.t. } & \beta(1-\pi) V^{L} \leq V-\pi \beta \bar{V}
\end{array}\right.
$$

The first order condition for $V^{L}$ is

$$
W^{\prime}\left(V^{L}\right) \geq \frac{1-f^{-1^{\prime}}\left(\frac{V-\beta V^{L}}{\pi p}\right) \frac{1}{\pi p}}{1-\pi}+\mu, \text { with equality if } \quad V^{L}<\bar{V},
$$

where $\mu \geq 0$ is the Lagrangian multiplier on the constraint. By the Envelope theorem,

$$
W^{\prime}(V)=1-f^{-1^{\prime}}\left(\frac{V-\beta V^{L}}{\pi p}\right) \frac{1}{\pi p}+\mu .
$$


Note that $V_{1}=\beta \pi \bar{V}+(1-\pi) V^{L}\left(V_{1}\right)<\beta \bar{V}$. So $V$ can fall in $\left[V_{1}, \beta \bar{V}\right)$ or $[\beta \bar{V}, \bar{V}]$. First, consider $V \in[\beta \bar{V}, \bar{V}]$. In this case, the constraint is not binding, since $(1-\pi) p f(l(V))>0 \geq \beta \bar{V}-V$. So $\mu=0$. And $W^{\prime}\left(V^{L}(V)\right) \geq \frac{W^{\prime}(V)}{1-\pi}>W^{\prime}(V)$. This implies $V^{L}(V)<V$. So $V^{L}(V)<\bar{V}$, which gives us equality in the first order condition, $W^{\prime}\left(V^{L}(V)\right)=\frac{W^{\prime}(V)}{1-\pi}$. Since $\beta \bar{V}>V_{1}>V_{r}, W(V)$ is strictly concave on $[\beta \bar{V}, \bar{V}]$. So $W^{\prime}\left(V^{L}(V)\right)$ is strictly decreasing in $V$, and hence $V^{L}(V)$ is strictly increasing in $V$. Now consider $V \in\left[V_{1}, \beta \bar{V}\right)$. First note that $V^{L}(V) \leq \frac{V-\pi \beta \bar{V}}{\beta(1-\pi)}<\frac{\beta \bar{V}-\pi \beta \bar{V}}{\beta(1-\pi)}=\bar{V}$. So

$$
\begin{aligned}
W^{\prime}\left(V^{L}(V)\right) & =\frac{1-f^{-1^{\prime}}\left(\frac{V-\beta V^{L}(V)}{\pi p}\right) \frac{1}{\pi p}}{1-\pi}+\mu(V) \\
& =\frac{1-f^{-1^{\prime}}\left(\frac{V-\beta V^{L}(V)}{\pi p}\right) \frac{1}{\pi p}}{1-\pi}+W^{\prime}(V)-\left\{1-f^{-1^{\prime}}\left(\frac{V-\beta V^{L}}{\pi p}\right) \frac{1}{\pi p}\right\} \\
& =\frac{\pi}{1-\pi}\left\{1-f^{-1^{\prime}}\left(\frac{V-\beta V^{L}(V)}{\pi p}\right) \frac{1}{\pi p}\right\}+W^{\prime}(V) .
\end{aligned}
$$

By (iii), $l(V)=\frac{V-\beta V^{L}(V)}{\pi p}<l^{\star}(p)$, so $f^{-1^{\prime}}\left(\frac{V-\beta V^{L}(V)}{\pi p}\right)<f^{-1^{\prime}}\left(f\left(l^{\star}(p)\right)\right)=\frac{1}{f^{\prime}\left(l^{\star}(p)\right)}=\pi p$. And hence $W^{\prime}\left(V^{L}(V)\right)>W^{\prime}(V)$, which implies $V^{L}(V)<V$. Also,

$$
W^{\prime}\left(V^{L}(V)\right)=\frac{W^{\prime}(V)-\mu(V)}{1-\pi}+\mu(V)=\frac{W^{\prime}(V)}{1-\pi}-\frac{\pi}{1-\pi} \mu(V) .
$$

Consider any $V, V^{\prime} \in\left[V_{1}, \beta \bar{V}\right), V^{\prime}>V$. Suppose $V^{L}\left(V^{\prime}\right) \leq V^{L}(V)$. Then

$$
W^{\prime}\left(V^{L}\left(V^{\prime}\right)\right)=\frac{W^{\prime}\left(V^{\prime}\right)}{1-\pi}-\frac{\pi}{1-\pi} \mu\left(V^{\prime}\right) \geq W^{\prime}\left(V^{L}(V)\right)=\frac{W^{\prime}(V)}{1-\pi}-\frac{\pi}{1-\pi} \mu(V) .
$$

Since $W^{\prime}\left(V^{\prime}\right) \leq W^{\prime}(V), \mu\left(V^{\prime}\right) \leq \mu(V)$. On the other hand, since $V^{\prime}-\beta V^{L}\left(V^{\prime}\right)>V-\beta V^{L}(V)$, and $f^{-1}$ is strictly convex, $f^{-1^{\prime}}\left(\frac{V^{\prime}-\beta V^{L}\left(V^{\prime}\right)}{1-\pi}\right)>f^{-1^{\prime}}\left(\frac{V-\beta V^{L}(V)}{1-\pi}\right)$. So $W^{\prime}\left(V^{L}\left(V^{\prime}\right)\right)=\frac{1-f^{-1^{\prime}}\left(\frac{V^{\prime}-\beta V^{L}\left(V^{\prime}\right)}{\pi p}\right) \frac{1}{\pi p}}{1-\pi}+$ $\mu\left(V^{\prime}\right)<\frac{1-f^{-1^{\prime}}\left(\frac{V-\beta V^{L}(V)}{\pi p}\right) \frac{1}{\pi p}}{1-\pi}+\mu(V)=W^{\prime}\left(V^{L}(V)\right)$. This implies $V^{L}\left(V^{\prime}\right)>V^{L}(V)$, which contradicts our assumption that $V^{L}\left(V^{\prime}\right) \leq V^{L}(V)$. So $V^{L}\left(V^{\prime}\right)>V^{L}(V)$ for any $V^{\prime}, V \in\left[V_{1}, \bar{V}\right), V^{\prime}>V$, i.e., $V^{L}(V)$ is strictly increasing on $\left[V_{1}, \bar{V}\right)$. In summary, $V^{L}(V)<V$ and strictly increasing on both $\left[V_{1}, \beta \bar{V}\right)$ and $[\beta \bar{V}, \bar{V}]$, so $V^{L}(V)<V$ on $\left[V_{1}, \bar{V}\right]$. And by continuity, $V^{L}(V)$ is strictly increasing on $\left[V_{1}, \bar{V}\right]$.

(v) In $\left(P_{2}\right)$, since the incentive constraint (10) is binding, $\tau(V)=\beta \bar{V}-V^{L}(V)$. Since $V^{L}(V)<$ $V \leq \bar{V}, \tau(V)>0$. And since $V^{L}(V)$ is strictly increasing in $V, \tau(V)$ is strictly decreasing in $V$.

(vi) Consider the problem $\left(P^{\prime}\right)$ formulated in part (iii) for some $V \in\left[V_{1}, \bar{V}\right]$. Note that the limited liability constraint is binding for $V=V_{1}$. Since $l(V)>0$ for $V>0$, the constraint is not binding for $V \geq \beta \bar{V}$. By continuity, there exists $\hat{V} \in\left[V_{1}, \beta \bar{V}\right)$, such that the limited liability constraint is binding for $V \in\left[V_{1}, \hat{V}\right]$, and not binding for $V \in(\hat{V}, \bar{V}]$. For $V \in(\hat{V}, \bar{V}], l(V)$ satisfies the first order condition

$$
\pi p f^{\prime}(l(V))=\frac{1}{1-(1-\pi) W^{\prime}\left(V^{L}(V)\right)} .
$$

Since $V^{L}(V)$ is strictly increasing and $W$ is strictly concave on $(\hat{V}, \bar{V}], f^{\prime}(l(V))$ is strictly decreasing, i.e., $l(V)$ is strictly increasing in $V$. 


\section{PROOF of LEMMA 4:}

Since the periodic profit function $\pi p f(l)-l$ is continuous and strictly increasing in $p, \hat{W}(V ; p)$ is continuous and strictly increasing in $p$. And hence $\hat{W}(V ; p)-V$ is continuous and strictly increasing in $p$. So $V_{0}(p)$ is continuous and strictly increasing in $p$ as long as a solution to $\left(P_{3}\right)$ exists at $p$.

\section{PROOF of PROPOSITION 5:}

Suppose $\mu_{t}^{\prime}(V ; p)=\kappa \mu(V ; p), E_{t+1}^{\prime}=\kappa E_{t+1}$, where $\kappa>0$ is an arbitrary real number. Since for every $A \in \mathcal{V}(p), \mu_{t}(A ; p)=0$ implies $\mu_{t}^{\prime}(A ; p)=0, \mu_{t}^{\prime}$ is absolutely continuous with respect to $\mu_{t}$. By Radon-Nikodym Theorem, $d \mu_{t}^{\prime}=\kappa d \mu$. So

$$
\begin{aligned}
\mu_{t+1}^{\prime}( & A ; p)=\int\left\{\pi\left(1-\alpha\left(V^{H}(V)\right)\right) \chi_{A}\left(V_{c}\left(V^{H}(V)\right)\right)\right. \\
& \left.+(1-\pi)\left(1-\alpha\left(V^{L}(V)\right)\right) \chi_{A}\left(V_{c}\left(V^{L}(V)\right)\right)\right\} \mu_{t}^{\prime}(d V ; p)+E_{t+1}^{\prime} \chi_{A}\left(V_{0}(p)\right) \\
= & \int\left\{\pi\left(1-\alpha\left(V^{H}(V)\right)\right) \chi_{A}\left(V_{c}\left(V^{H}(V)\right)\right)\right. \\
& \left.+(1-\pi)\left(1-\alpha\left(V^{L}(V)\right)\right) \chi_{A}\left(V_{c}\left(V^{L}(V)\right)\right)\right\} \kappa \mu_{t}(d V ; p)+\kappa E_{t+1} \chi_{A}\left(V_{0}(p)\right) \\
= & \kappa\left\{\int \left\{\pi\left(1-\alpha\left(V^{H}(V)\right)\right) \chi_{A}\left(V_{c}\left(V^{H}(V)\right)\right)\right.\right. \\
& \left.\left.+(1-\pi)\left(1-\alpha\left(V^{L}(V)\right)\right) \chi_{A}\left(V_{c}\left(V^{L}(V)\right)\right)\right\} \mu_{t}(d V ; p)+E_{t+1} \chi_{A}\left(V_{0}(p)\right)\right\} \\
= & \kappa \mu_{t+1}(A ; p) .
\end{aligned}
$$

\section{PROOF of THEOREM 1(Sketch):}

For any given distribution of firms, $\mu$, there exists a unique $p$ that satisfies condition (ii) in the definition of equilibrium. Denote $p^{0}$ as the output price corresponding to $\mu=0 . p^{0}$ may be infinity. Define $I^{\star}=\hat{W}\left(M ; p^{0}\right)$, then if $I<I^{\star}$, the problem $\left(P_{3}\right)$ has a solution at $p^{0}$ and $V_{0}\left(p^{0}\right)>M$. Note that $\left(P_{3}\right)$ has no solution for sufficiently small $p$, since $\hat{W}(V ; p=0)=\beta S<I-M$, for $\forall V>0$. Define $p^{1}=\min \{p: \exists V \in[0, \bar{V}(p)]$, s.t. $\hat{W}(V ; p)-V \geq I-M\}$, i.e., $p^{1}$ is the smallest $p$ at which $\left(P_{3}\right)$ has a solution. Since $\hat{W}(V ; p)-V$ is continuous and strictly increasing in $p, p^{1}$ is well defined and strictly greater than zero. And $p^{1}$ is continuous and strictly decreasing in $M$. So by Lemma $4, V_{0}\left(p^{1}(M)\right)$ is continuous and strictly decreasing in $M$. Note that for $M$ close to zero, $V_{0}\left(p^{1}(M)\right)>M$. And for $M$ close to $I, V_{0}\left(p^{1}(M)\right)$ is close to zero, which is less than $M$. So there exists $M^{\star}, 0<M^{\star}<I$, such that $V_{0}\left(p^{1}\left(M^{\star}\right)\right)=M^{\star}$. If $M \geq M^{\star}$, then $V_{0}\left(p^{1}(M)\right) \leq M$. By the continuity and monotonicity of $V_{0}(p)$, there exists a unique $p^{\star}, p^{1}(M) \leq p^{\star}<p^{0}$, such that $V_{0}\left(p^{\star}\right)=M$.

With $p^{\star}$, decision rules $l\left(V ; p^{\star}\right), V^{H}\left(V ; p^{\star}\right), V^{L}\left(V ; p^{\star}\right), \tau\left(V ; p^{\star}\right), \alpha\left(V ; p^{\star}\right)$ and $V_{c}\left(V ; p^{\star}\right)$ as well as value functions $W\left(V ; p^{\star}\right)$ and $\hat{W}\left(V ; p^{\star}\right)$ can be uniquely determined by solving the contracting problem $\left(P_{1}\right)$ and $\left(P_{2}\right)$.

The final step is to establish the existence and uniqueness of an invariant measure $\mu^{\star}$ and mass of entry $E^{\star}$ that satisfy the equilibrium conditions. First let $E^{t} \equiv 1$ in Eq. (15), then the operator $T^{\star}$ has a unique fixed point $\mu$. It's not hard to show that the transition function defined by the decision rules is monotone, has the Feller property, and satisfies the mixing condition of Assumption 12.1 of Stokey and Lucas (1989). Since entry is positive and 0 is not in the ergodic set of $\mu$ (firms with equity values equal to zero are scrapped for sure and cannot survive to the continuation stage), $\mu$ puts all positive mass on firms with equity values greater than zero. Since $l(V)>0$ for 
$V>0$, the aggregate output $Y\left(\mu ; p^{\star}\right)>0$. Let $E^{\star}$ be determined by $Q^{\star} \equiv D^{-1}\left(p^{\star}\right)=E^{\star} Y\left(\mu ; p^{\star}\right)$. Since $p^{\star}<p^{0}, Q^{\star}>0$. So $E^{\star}>0$. By the linear homogeneity of $T^{\star}, \mu^{\star}=E^{\star} \mu$ is the unique fixed point of $T^{\star}$ when entry is $E^{\star}$.

\section{A BRIEF DESCRIPTION OF THE SOLUTION METHOD ${ }^{18}$}

The behavior of the industry cannot be characterized analytically. We construct a numerical approximation to the stationary competitive equilibrium with entry and exit defined in Section 3.6. For a given set of parameter values, the computation strategy involves the following steps.

1. Solving the dynamic contracting problems and computing the optimal decision rules, which involves an iteration on the following steps.

- For a given $W$, find its fixed point $\bar{V}$;

- Solve the problem $\left(P_{2}\right)$ to obtain $\hat{W}$;

- Solve the problem $\left(P_{1}\right)$ to obtain a new $W$.

$\left(\left(\left(P_{1}\right)\right.\right.$ and $\left(P_{2}\right)$ are solved by piecewise linear approximation. The state space $[0, \bar{V}]$ is divided into 100 grids, with finer grids for smaller regions).

2. Solving the entry problem $\left(P_{3}\right)$ to determine a firm's initial equity value $V_{0}$.

3. Iterating on (15) to compute the stationary measure $\mu$ with $E=1$, and

4. Using an exogenously given level of total labor demand to determine the equilibrium level of entry $E^{\star}$ and the corresponding stationary measure $\mu^{\star}$.

\footnotetext{
${ }^{18}$ Details and Matlab codes are available upon request
} 